\title{
Article
}

\section{Experimental and DFT Insights on Microflower g-C3N4/BiVO4 Photocatalyst for Enhanced Photoelectrochemical Hydrogen Generation from Lake water}

Mohamad Fakhrul Ridhwan Samsudin, Habib Ullah, Robabeh

Bashiri, Norani Muti Mohamed, Suriati Sufian, and Yun Hau Ng

ACS Sustainable Chem. Eng., Just Accepted Manuscript • DOI: 10.1021/

acssuschemeng.0c02063 • Publication Date (Web): 08 Jun 2020

Downloaded from pubs.acs.org on June 11, 2020

\section{Just Accepted}

"Just Accepted" manuscripts have been peer-reviewed and accepted for publication. They are posted online prior to technical editing, formatting for publication and author proofing. The American Chemical Society provides "Just Accepted" as a service to the research community to expedite the dissemination of scientific material as soon as possible after acceptance. "Just Accepted" manuscripts appear in full in PDF format accompanied by an HTML abstract. "Just Accepted" manuscripts have been fully peer reviewed, but should not be considered the official version of record. They are citable by the Digital Object Identifier (DOIB). "Just Accepted" is an optional service offered to authors. Therefore, the "Just Accepted" Web site may not include all articles that will be published in the journal. After a manuscript is technically edited and formatted, it will be removed from the "Just Accepted" Web site and published as an ASAP article. Note that technical editing may introduce minor changes to the manuscript text and/or graphics which could affect content, and all legal disclaimers and ethical guidelines that apply to the journal pertain. ACS cannot be held responsible for errors or consequences arising from the use of information contained in these "Just Accepted" manuscripts. 


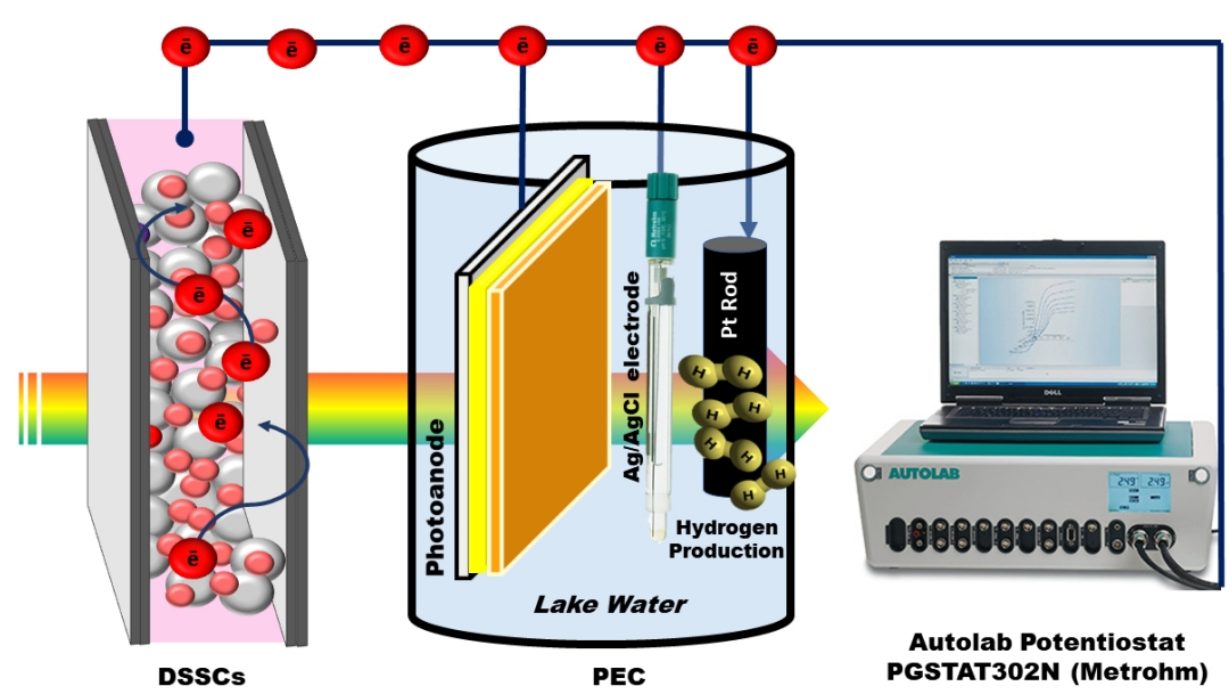

PEC-DSSCs setup of the g-C3N4/BiVO4 microflower photocatalyst in generating hydrogen from lake water $338 \times 190 \mathrm{~mm}(96 \times 96 \mathrm{DPI})$ 


\section{Experimental and DFT Insights on Microflower g- $\mathrm{C}_{3} \mathrm{~N}_{4} / \mathrm{BiVO}_{4}$ Photocatalyst for Enhanced Photoelectrochemical Hydrogen Generation from Lake water}

Mohamad Fakhrul Ridhwan Samsudin ${ }^{\mathrm{a}}$, Habib Ullah ${ }^{\mathrm{b}}$, Robabeh Bashiric, Norani Muti Mohamed ${ }^{\mathrm{c}}$, Suriati Sufian ${ }^{\mathrm{a}, \mathrm{c}^{*}}$, Yun Hau $\mathrm{Ng}^{\mathrm{d}}$

a Chemical Engineering Department, Universiti Teknologi PETRONAS, 32610, Bandar Seri Iskandar, Perak, Malaysia.

b Renewable Energy Group, College of Engineering, Mathematics and Physical Sciences, University of Exeter, Penryn Campus, Cornwall, TR10 9FE, United Kingdom

c Centre of Innovative Nanostructures \& Nanodevices (COINN), Universiti Teknologi PETRONAS, 32610, Bandar Seri Iskandar, Perak, Malaysia

d School of Energy and Environment, City University of Hong Kong, Kowloon, Hong Kong SAR, P. R. China.

Corresponding authors: S. Sufian (suriati@utp.edu.my) / Tel: +605-3687587 


\begin{abstract}
Herein, an experimental and Density Functional Theory (DFT) analysis of the composite g$\mathrm{C}_{3} \mathrm{~N}_{4} / \mathrm{BiVO}_{4}$ microflower photocatalysts were comprehensively discussed. A remarkable photoelectrocatalytic solar hydrogen production has been observed for the as-developed photocatalysts, with different loading amounts of $\mathrm{g}-\mathrm{C}_{3} \mathrm{~N}_{4}(0.1,0.4,0.8$, and 1.2 wt.\%), using lake water without the addition of sacrificial reagents. The 0.8 wt. $\%$ g- $\mathrm{C}_{3} \mathrm{~N}_{4} / \mathrm{BiVO}_{4}$ microflower photocatalyst evinced remarkable photoelectrocatalytic activity of $21.4 \mathrm{mmol} / \mathrm{h}$ of hydrogen generated in comparison to other samples with an AQE of $4.27 \%$ at $420 \mathrm{~nm}$. In addition, the photocurrent density of 0.8 wt. $\%$ g- $\mathrm{C}_{3} \mathrm{~N}_{4} / \mathrm{BiVO}_{4}$ microflower was two-fold higher than that of pure $\mathrm{BiVO}_{4}$. This was attributed to its better crystallinity and optical properties; confirmed from XRD and DR-UV-Vis analysis. The DFT analysis further corroborated that the efficient photocharge carrier separation and limited photocharge carrier recombination corresponded to the synergistic effect of the band offset and built-in electric field.
\end{abstract}

Keyword: $\mathrm{BiVO}_{4}, \mathrm{~g}-\mathrm{C}_{3} \mathrm{~N}_{4}$, photoelectrochemical cell, density functional theory, hydrogen, lake water. 


\section{Introduction}

Over the past few decades, photoelectrochemical (PEC) solar water splitting has gained significant interest in the scientific community, as an alternative to current fossil fuel technologies. ${ }^{1-3}$ The PEC solar water splitting is highly dependent on the efficiency of photocatalyst materials. Nevertheless, the performances of conventional photocatalysts are greatly hampered due to several obstacles such as infinitesimal light conversion efficiency, photocorrosion, and recombination of the photocharge carriers. ${ }^{4,5}$ Considerable efforts have been dedicated to find and develop highly efficient photocatalytic materials that can alleviate these issues, facing by conventional photocatalysts. Ideally, a practical photocatalyst material must fulfil the following requirements (i) visible-light-driven material, (ii) proper band edge location for water splitting reaction, (iii) do not undergo photocorrosion and (iv) smooth photocharge carrier separation and migration. ${ }^{6-8}$

Up to date, photocatalysts which possess microstructure-dependent properties has gained much interest owing to the favourable structural properties that can significantly improve the photocatalytic performance. ${ }^{9,10}$ Specifically, the transformation of one-dimensional (1D) nanostructures into three-dimensional (3D) microstructures has been a recent focus of interest due to unique morphology and surface structure properties. ${ }^{11,12}$ Generally, the PEC reaction takes place at the surface of photocatalyst, where all the photocharge carriers reside and initiate the photocatalytic process. Thus, by tailoring the surface structure of the photocatalyst, it is anticipated that the overall PEC water splitting reaction could be significantly enhanced.

Bismuth vanadate $\left(\mathrm{BiVO}_{4}\right)$ is one of the many visible-light-driven photocatalysts which have been extensively explored for the PEC water splitting system. ${ }^{13,14}$ This is attributed to its peculiar merits such as visible-light active material with a bandgap energy of $\sim 2.4 \mathrm{eV}$, suitable band edge 
location for water splitting reaction, and highly stable against photocorrosion. ${ }^{15}$ Nevertheless, the existing limitations of single photocatalyst such as the fast recombination rate of photocharge carriers, sluggish water oxidation kinetics, and short holes diffusion length has circumscribed the aptness of this material. ${ }^{8,16}$ To address these issues, our group has performed various strategies including defect strategies, facet engineering, and formation of the heterostructure system. ${ }^{17-20}$

Among them, the formation of the heterostructure system with other semiconductor materials shows a great promise in the enhancement of PEC performance. ${ }^{21-23}$ This enhancement is owing to the heterostructure system that facilitates the separation and migration of the photocharge carrier to a better degree where more available electrons and holes can participate in the photocatalytic reaction. Graphitic carbon nitride $\left(\mathrm{g}-\mathrm{C}_{3} \mathrm{~N}_{4}\right)$ is an emerging semiconductor material with moderate bandgap energy possesses a fascinating property, particularly a wellmatched band structure that is suitable for the formation of a heterostructure system with $\mathrm{BiVO}_{4}$ materials. ${ }^{22,24}$ The compatibility between $\mathrm{g}^{-} \mathrm{C}_{3} \mathrm{~N}_{4}$ and $\mathrm{BiVO}_{4}$ to form the heterostructure system is anticipated to demonstrate a smooth transfer of the generated photocharge carries at the heterostructure interface. A smooth photocharge carrier transfer within the heterostructure system is possible due to the minimum resistance at the heterostructure interface, which results in minimizing the photocharge carrier recombination and thus enhancing the overall photoelectrocatalytic performance.

Herein, a novel $\mathrm{g}^{-} \mathrm{C}_{3} \mathrm{~N}_{4} / \mathrm{BiVO}_{4}$ microflower photocatalyst was prepared and its photoelectrocatalytic hydrogen evolution performance was evaluated. The effect of different amounts of $\mathrm{g}_{-} \mathrm{C}_{3} \mathrm{~N}_{4}$ loading integrated onto $3 \mathrm{D} \quad \mathrm{BiVO}_{4}$ microflower photocatalyst was systematically studied. In addition, the reusability and stability analyses were performed to investigate the photocorrosion properties. Moreover, the study on the potential of hydrogen 
evolution from lake water is hardly been found. Most of the previous literature is focussed on the development of composite photocatalyst for PEC hydrogen production, using a chemical-based electrolyte. Thus, the mobilization of natural lake water as an alternative for the conventional chemical-based electrolyte solution will embark on a new paradigm in the photocatalytic field and thus facilitate the readiness of this technology for practical usage. Finally, we also performed periodic density functional theory (DFT) for $\mathrm{g}-\mathrm{C}_{3} \mathrm{~N}_{4} / \mathrm{BiVO}_{4}$ heterostructure to determine their interaction and counter check our experimental data.

\section{Materials and Methods}

\section{Synthesis of $\mathrm{g}-\mathrm{C}_{3} \mathrm{~N}_{4} / \mathrm{BiVO}_{4}$ Microflower Photocatalyst}

A modified hydrothermal method and thermal polycondensation of urea methods have been employed in order to prepare the pure $3 \mathrm{D} \mathrm{BiVO}_{4}$ and $g-\mathrm{C}_{3} \mathrm{~N}_{4}$ samples, respectively. Details on the synthesis protocols have been comprehensively discussed in our previous reports. ${ }^{13,25}$ Meanwhile, a wet-impregnation method was used to prepare a series of the composite $\mathrm{g}-\mathrm{C}_{3} \mathrm{~N}_{4} / \mathrm{BiVO}_{4}$ microflower samples with particular amounts of $\mathrm{g}-\mathrm{C}_{3} \mathrm{~N}_{4}$ loading. Generally, $0.1,0.4,0.8$, and 1.2 wt.\% of $g-\mathrm{C}_{3} \mathrm{~N}_{4}$ were separately added into a beaker, containing $1 \mathrm{~g}$ of $\mathrm{BiVO}_{4}$ microflower. Prior to the one hour stirring process, $40 \mathrm{~mL}$ of deionized water was added. Then, the suspension was heated until it becomes a thick orange-yellowish slurry. The collected slurry was then dried in an oven at $80^{\circ} \mathrm{C}$ for 24 hours.

\section{Physicochemical Characterization}

The physicochemical properties of the photocatalyst samples were characterized using several characterization techniques. The crystallinity and morphology of the materials were 
examined using XRD (X'Pert3 powder and Empyrean, PANlytical) and FESEM-EDX (Zeiss Supra 55VP). The chemical stability of the materials was investigated using FTIR (Shimadzu 8400S). The optical properties of the materials were examined using DR-UV-Vis (Cary 100) spectrophotometer. The BET surface area and porosity of the materials were measured using Micromeritic ASAP 2000.

\section{Photoelectrochemical (PEC) Measurement}

A standard three-electrode cell configuration system which composed of working electrode (the as-developed g- $\mathrm{C}_{3} \mathrm{~N}_{4} / \mathrm{BiVO}_{4}$ photocatalyst), reference electrode $(\mathrm{Ag} / \mathrm{AgCl} /$ saturated $\mathrm{KCl})$ and counter electrode (Platinum rod) were employed. The measurement was performed using Autolab potentiostat PGSTAT302N (Methrom). A doctor blading technique was used in order to prepare the working electrode as shown in Figure 1. The details of the fabrication process can be found elsewhere. ${ }^{25}$ A $500 \mathrm{~W}$ halogen lamp and $0.5 \mathrm{M} \mathrm{Na}_{2} \mathrm{SO}_{4}$ solution were employed during the measurement. Details description of the procedure for measuring the photocurrent density versus applied potential (I-V) and electrochemical impedance spectroscopy (EIS) can be found in our previous work. ${ }^{26,27}$ 


\section{Photoelectrocatalytic Hydrogen Production}

Figure 2 depicts the schematic PEC-DSSC setup used in this photoelectrocatalytic hydrogen production study. A $200 \mathrm{~mL}$ of lake water solution was used without the addition of any chemical scavengers. The water with a $\mathrm{pH}$ of 7.2 was collected from local lake water. A $500 \mathrm{~W}$ halogen lamp was utilized, and the intensity was adjusted to $100 \mathrm{~mW} / \mathrm{cm}^{2}$. A Multiple Gas Analyzer (SRI Instruments 8610-0071) was employed to analyze the hydrogen production. 


\section{Computational Methodology}

The computational study, in the view of the density functional theory (DFT), were performed using Quantum-ATK. In addition, the computational results were deciphered using VESTA and Virtual NanoLab Version 2019.3. The details on the DFT analysis of the pure $\mathrm{BiVO}_{4}$ has been reported previously. ${ }^{19}$ In addition, the readers are directed towards our previous works for more detail's description of the theoretical procedure in examining this DFT analysis. ${ }^{17,18,28}$ The structural and energy optimization were scrutinized using GGA-PBE and DZP. The MonkhorstPack k-grid $\left(7 \times 7 \times 3\right.$ for $\mathrm{BiVO}_{4}$ and $7 \times 7 \times 7$ for monolayer $\left.g-\mathrm{C}_{3} \mathrm{~N}_{4}\right)$ with an energy cut-off of 1200 $\mathrm{eV}$ was used in this work.

\section{Results and Discussion}




\section{Crystallographic and Morphological Properties}

Figure 3 delineates the XRD analysis of the $\mathrm{g}-\mathrm{C}_{3} \mathrm{~N}_{4} / \mathrm{BiVO}{ }_{4}$ microflower photocatalysts prepared at the various amount of $g-\mathrm{C}_{3} \mathrm{~N}_{4}$ loading. The peak splitting observed at 24.7 and $25.6^{\circ}$ of $2 \theta$ corresponds to the tetragonal structure of $\mathrm{BiVO}_{4}$ (JCPDS card no. $14-0133$ ). Meanwhile, the detection of peak splitting located at $30.6,34.8,39.5$, and $48.5^{\circ}$ of $2 \theta$ coincided well with the monoclinic scheelite structure of the $\mathrm{BiVO}_{4}$ (JCPDS card no. $\left.14-0688\right) .{ }^{29,30}$ All these observed peaks indicate that the as-prepared $\mathrm{BiVO}_{4}$ was composed of two different types of structures; namely tetragonal and monoclinic scheelite-like structure. It is worthwhile to note that the intensity of the $\mathrm{BiVO}_{4}(121)$ crystal planes was weakened while that of (040) crystal planes was enhanced with respect to the increased in the amounts of $\mathrm{g}-\mathrm{C}_{3} \mathrm{~N}_{4}$ loadings. This phenomenon led us to conclude that the overloading of $\mathrm{g}-\mathrm{C}_{3} \mathrm{~N}_{4}$ photocatalyst could modulate the crystallinity of photocatalyst which preferably grow at a different orientation.

Generally, the $\mathrm{g}-\mathrm{C}_{3} \mathrm{~N}_{4}$ photocatalysts are composed of (100) and (002) crystal planes which can be observed at 13.9 and $25.6^{\circ}$ of the $2 \theta$, respectively. ${ }^{31,32}$ The strong peak intensity of (002) crystal planes indicates a graphite-like interlayer stacking microstructures with an interlayer distance of $d=0.326 \mathrm{~nm}$. This graphite-like interlayer stacking is tighter than the stacking of the graphene units with an interlayer distance of $d=0.353 \mathrm{~nm} .{ }^{33}$ This observation indicates the wellassimilated of the layers of the aromatic systems with the heteroatom substitution. Thus it leads to the localization of the electrons and stronger binding between the layers. ${ }^{24}$ Meanwhile, the detection of a weak (100) crystal planes based on the JCPDS card no. $01-0646$ in the composite g- $\mathrm{C}_{3} \mathrm{~N}_{4} / \mathrm{BiVO}_{4}$ microflower sample correspond to the tri-s-triazine unit in-planar ordering. ${ }^{28}$ 
Magnified XRD patterns at $25.6^{\circ}$ of the $2 \theta$ which corresponds to (002) crystal plane of the g- $\mathrm{C}_{3} \mathrm{~N}_{4}$ photocatalyst, were shown in Figure 3 (b). It can be seen that the (002) crystal plane of all g- $\mathrm{C}_{3} \mathrm{~N}_{4} / \mathrm{BiVO}_{4}$ sample were less broad and slightly blue-shifted in comparison to $0.8 \mathrm{wt} . \% \mathrm{~g}$ $\mathrm{C}_{3} \mathrm{~N}_{4} / \mathrm{BiVO}_{4}$ sample. This was presumably due to the internal stress left of the crystallization of $\mathrm{BiVO}_{4}$ and $\mathrm{g}-\mathrm{C}_{3} \mathrm{~N}_{4}$ in the form of the composite. ${ }^{34}$ Meanwhile, the peak at $13.9^{\circ}$ of $2 \theta$ which was attributed to the parental peak of the $\mathrm{g}-\mathrm{C}_{3} \mathrm{~N}_{4}$ sample was hardly visible in the composite sample. This might be due to the simultaneously decreased in the planar size and denser stacking of the g$\mathrm{C}_{3} \mathrm{~N}_{4}$ layers. ${ }^{22}$ On the other hand, the change in peak intensity and peak shifting position was observed in the as-developed $\mathrm{g}-\mathrm{C}_{3} \mathrm{~N}_{4} / \mathrm{BiVO}_{4}$ microflower photocatalysts. This statement further confirmed the successful integration of the $\mathrm{g}_{-} \mathrm{C}_{3} \mathrm{~N}_{4}$ and $\mathrm{BiVO}_{4}$ particles, to form a composite photocatalyst. ${ }^{35}$ Furthermore, there were no impurity peaks were detected except for the footprint of the parental photocatalysts.

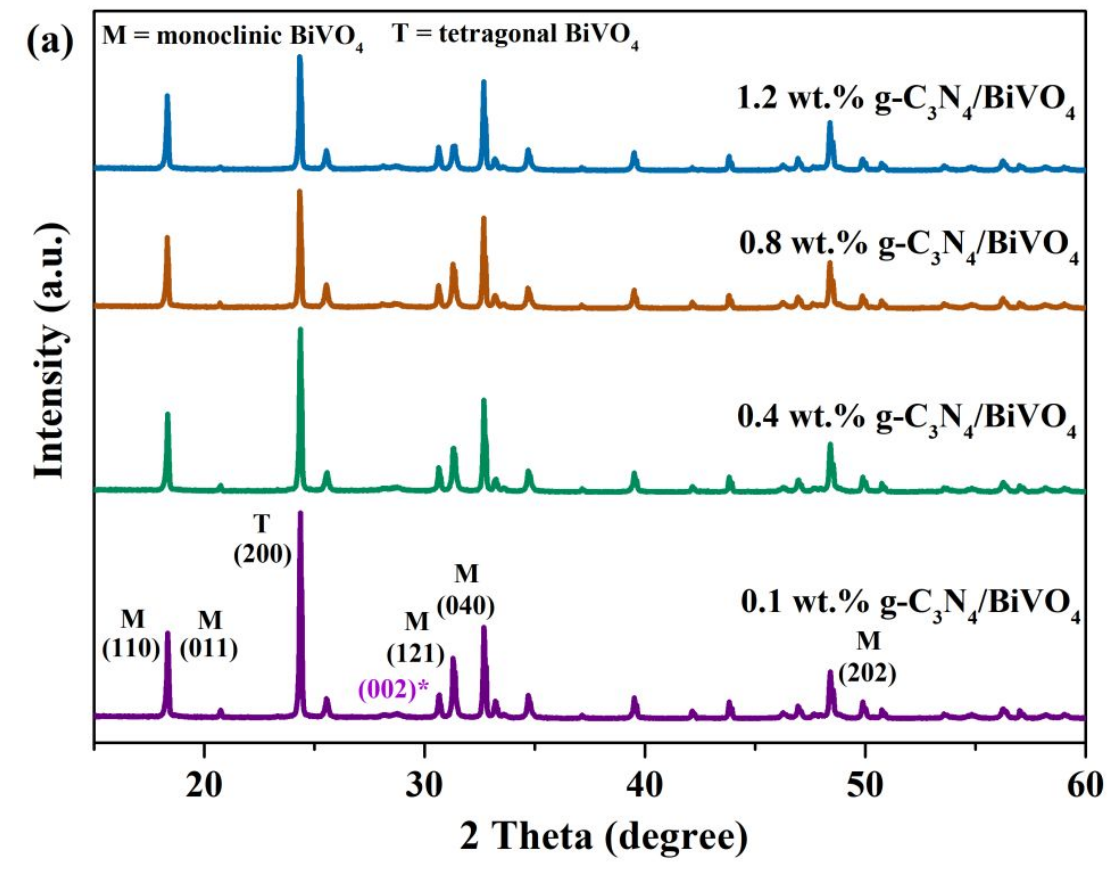




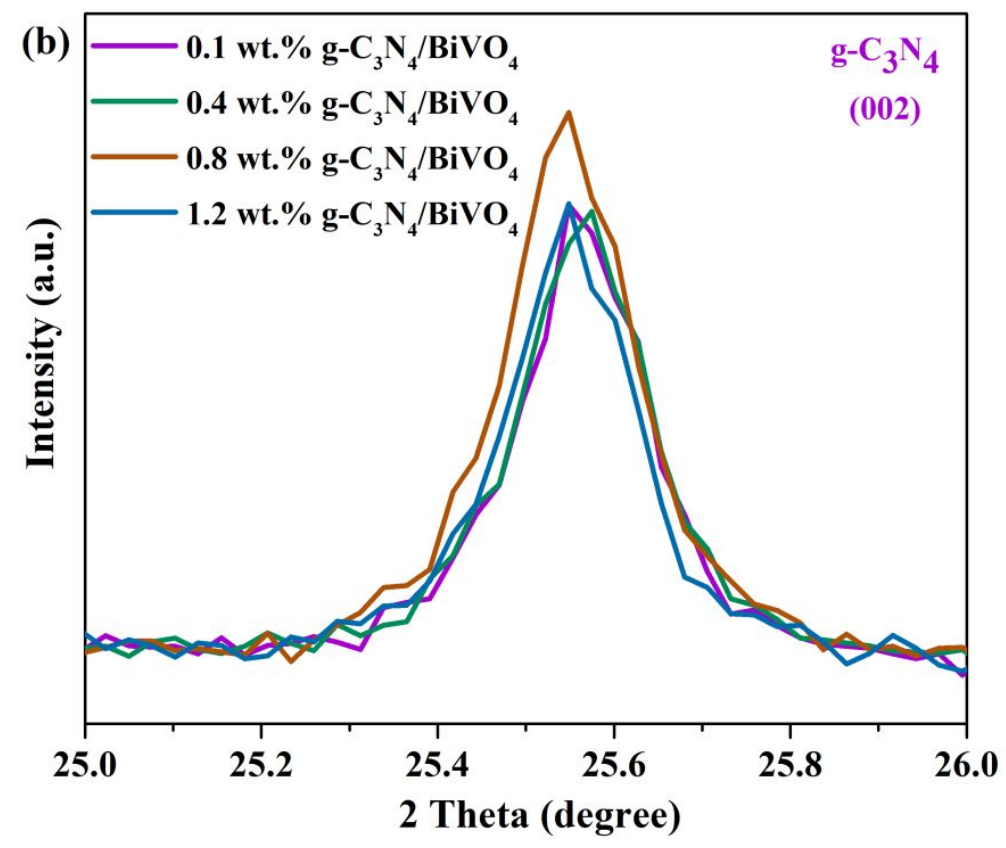

Figure 3: XRD analysis of the $\mathrm{g}-\mathrm{C}_{3} \mathrm{~N}_{4} / \mathrm{BiVO}_{4}$ microflower samples.

Figure 4 illustrated the morphological properties of the as-developed microflower photocatalysts which were examined using FESEM analysis. The panoramic view of all these samples shows a combination of 3D microflower shape-like structure and wrinkled layered structure which corresponds to the $\mathrm{BiVO}_{4}$ and $\mathrm{g}-\mathrm{C}_{3} \mathrm{~N}_{4}$ samples, respectively. The $3 \mathrm{D} \mathrm{BiVO}_{4}$ exhibits a typical blooming flower-like morphology with relatively sharp facets and edges. In addition, the microflower structure possesses a high symmetry as can be seen from the axial lines of the petals. Similarly, Ou et al. ${ }^{36}$ reported that they successfully developed a superstructure $\mathrm{BiVO}_{4}$ microflower via tailoring the $\mathrm{pH}$ of the solution. Meanwhile, the $\mathrm{g}-\mathrm{C}_{3} \mathrm{~N}_{4}$ particles were made up of the irregular folding with large particle size. ${ }^{37,38}$ The agglutinated $g-\mathrm{C}_{3} \mathrm{~N}_{4}$ particles were uniformly distributed onto the (010) crystal facet of the $3 \mathrm{D} \mathrm{BiVO}_{4}$ microflower, signifying the smooth photocharge carrier separation and migration. The reason behind this was the uniform 
and intimate contact between these two photocatalysts. The intimate contact between $g-\mathrm{C}_{3} \mathrm{~N}_{4}$ and $\mathrm{BiVO}_{4}$ particles is important as it can inhibit the rate of recombination of photocharge carriers and thus more available electron-hole pairs can participate in the photoelectrocatalytic reaction. ${ }^{30,39}$ Nevertheless, the overloading of the $\mathrm{g}-\mathrm{C}_{3} \mathrm{~N}_{4}$ photocatalyst in $1.2 \mathrm{wt} . \% \mathrm{~g}-\mathrm{C}_{3} \mathrm{~N}_{4} / \mathrm{BiVO}_{4}$ results in the agglomeration of the particle. This further deteriorates the photoelectrocatalytic hydrogen performance due to the blockage of active site traits. Additionally, the EDX analysis further confirmed that the as-developed composite composed of two materials; namely $\mathrm{g}_{-} \mathrm{C}_{3} \mathrm{~N}_{4}$ and $\mathrm{BiVO}_{4}$ photocatalyst, without any impurity as shown in Figure 4(b). Comparative analysis of FESEM and EDX led us to conclude that $\mathrm{g}-\mathrm{C}_{3} \mathrm{~N}_{4} / \mathrm{BiVO}_{4}$ microflower photocatalysts were successfully developed from the integration of $g-\mathrm{C}_{3} \mathrm{~N}_{4}$ and $3 \mathrm{D} \mathrm{BiVO}_{4}$ photocatalyst via a wet-impregnation method.

(a)

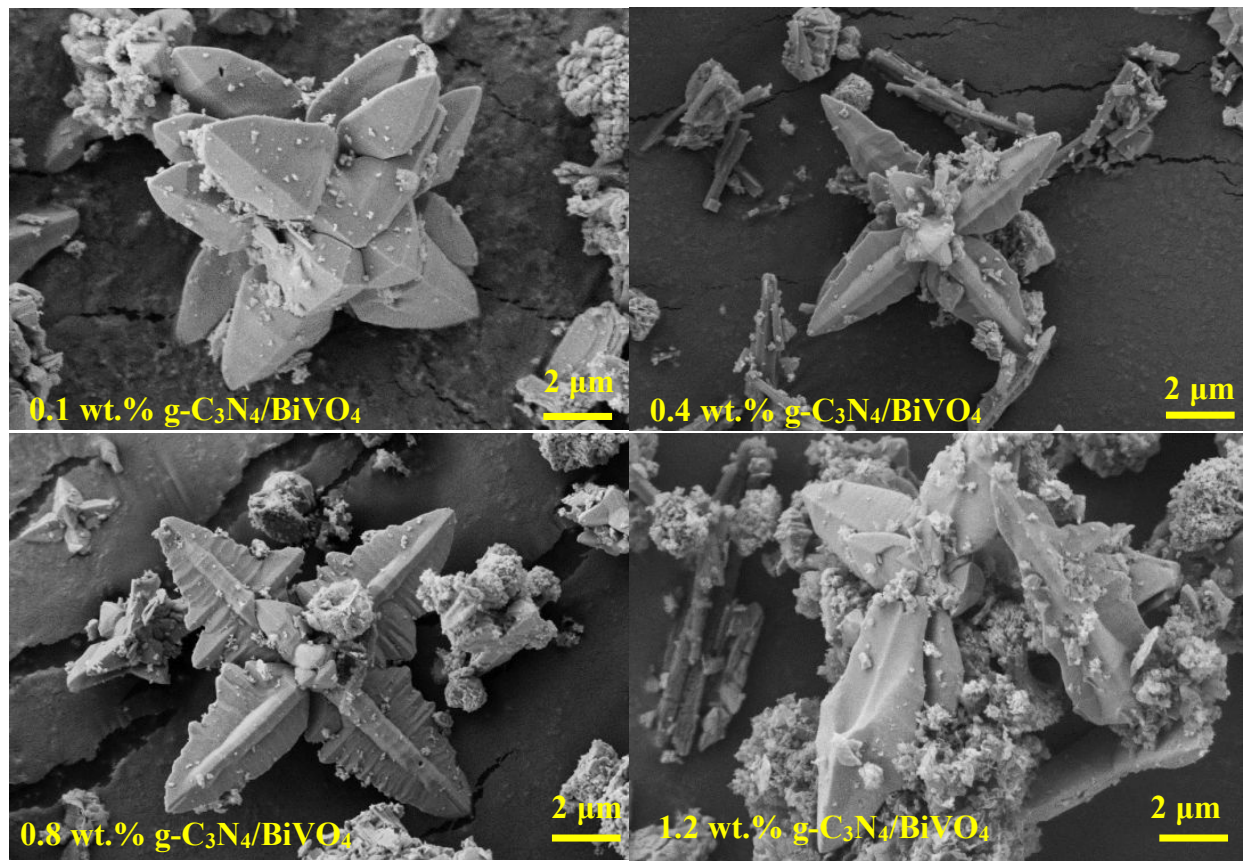


(b)
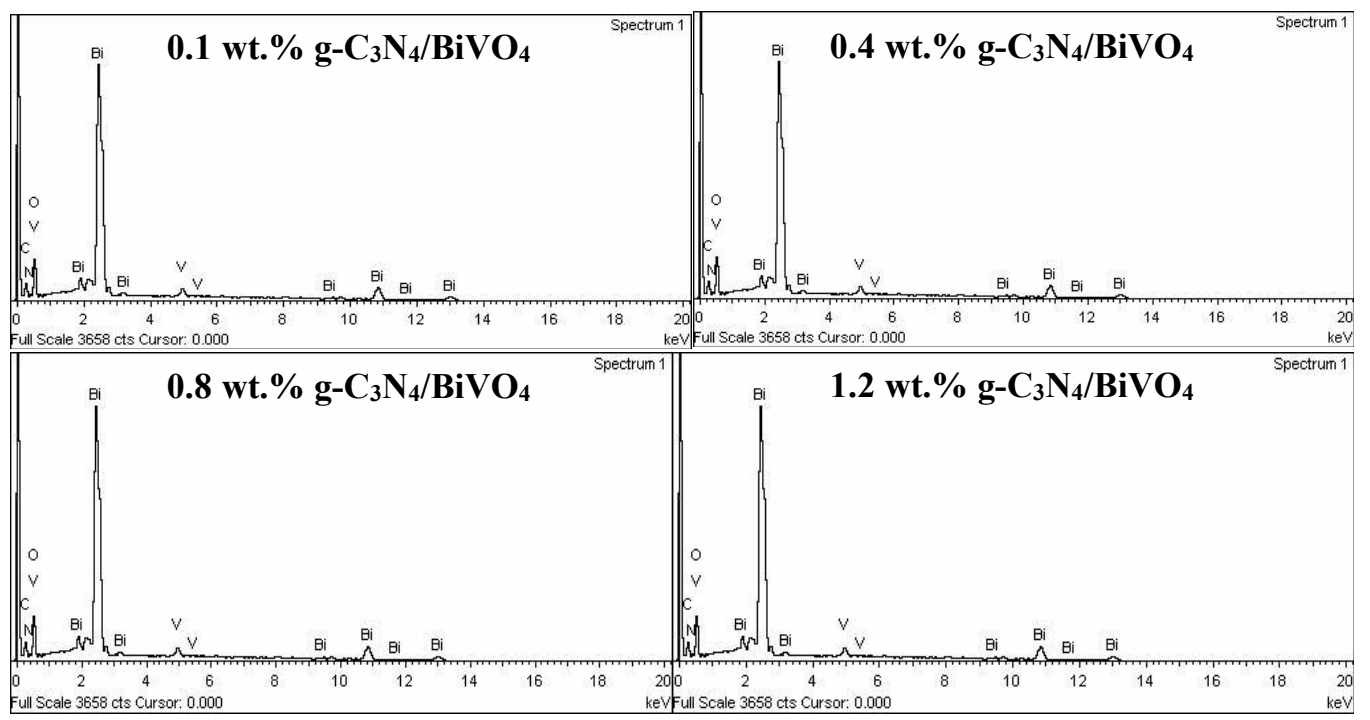

Figure 4: (a) FESEM micrograph images and (b) EDX spectrum survey of the $\mathrm{g}_{-} \mathrm{C}_{3} \mathrm{~N}_{4} / \mathrm{BiVO}_{4}$ microflower samples.

\section{Optical Properties}

Figure 5 (a) divulged that all samples possess strong visible-light absorption capacity, signifying the possibility of photocatalytic response up to $48 \%$ of solar energy. The bandgap energy of $\mathrm{g}-\mathrm{C}_{3} \mathrm{~N}_{4} / \mathrm{BiVO}_{4}$ samples was estimated from the Tauc plot calculation (see Figure 5 (b)). The typical bandgap energy of pure $\mathrm{BiVO}_{4}$ and $\mathrm{g}-\mathrm{C}_{3} \mathrm{~N}_{4}$ were 2.42 and $2.88 \mathrm{eV}$, respectively. This bandgap energy is within the range of the previously reported works. ${ }^{40,41}$ Additionally, the bandgap energy of composite $0.1,0.4,0.8$ and 1.2 wt.\% g- $\mathrm{C}_{3} \mathrm{~N}_{4} / \mathrm{BiVO}_{4}$ samples were 2.67, 2.70, 2.72 and $2.79 \mathrm{eV}$, respectively. Nevertheless, the overloading of the $\mathrm{g}-\mathrm{C}_{3} \mathrm{~N}_{4}$ sample has an adverse impact on the light absorption capacity of the sample. This adverse impact could significantly depreciate the overall photoelectrocatalytic performance due to the limited light absorption capacity. ${ }^{42}$ 

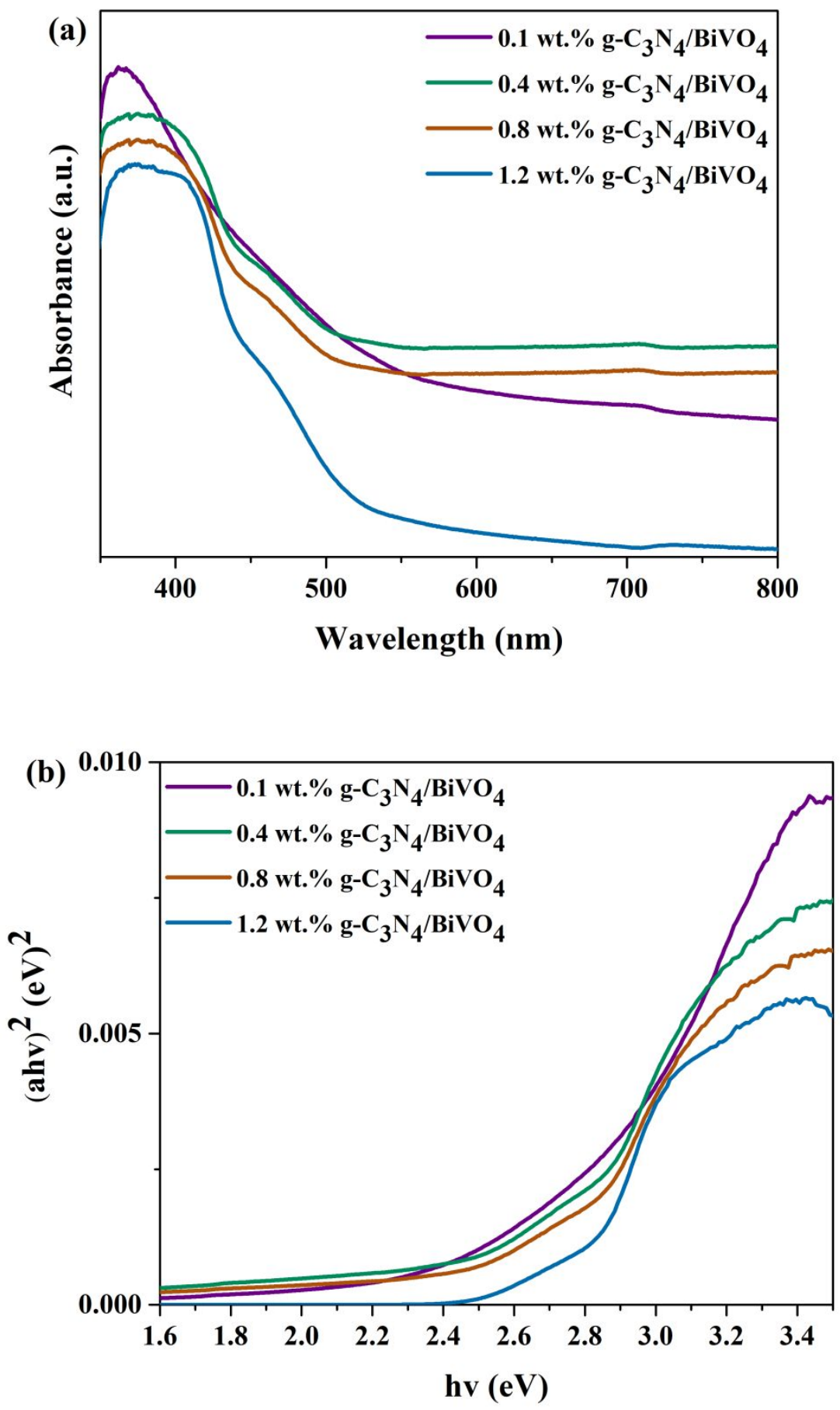

Figure 5: (a) DR-UV-Vis spectra and (b) Tauc plot of the $\mathrm{g}^{-} \mathrm{C}_{3} \mathrm{~N}_{4} / \mathrm{BiVO}_{4}$ microflower samples. 


\section{BET Analysis}

The textural properties of the composite microflower photocatalysts were scrutinized and summarized in Table 1 . The $0.8 \mathrm{wt} . \% \mathrm{~g}-\mathrm{C}_{3} \mathrm{~N}_{4} / \mathrm{BiVO}_{4}$ microflower photocatalyst has the highest BET surface area than the other samples which was consistent with the adsorption-desorption isotherm illustrated in Figure 6. Nevertheless, the overloading of the $g-\mathrm{C}_{3} \mathrm{~N}_{4}$ which was portrayed by the 1.2 wt. $\%$ g- $\mathrm{C}_{3} \mathrm{~N}_{4} / \mathrm{BiVO}_{4}$ sample had caused the surface area slightly decreased. This presumably due to the potential of the agglomeration of the particles which shielded the surface area as supported by the FESEM analysis as discussed previously (see Figure 4).

Table 1: BET analysis of the $\mathrm{g}-\mathrm{C}_{3} \mathrm{~N}_{4} / \mathrm{BiVO}_{4}$ microflower samples.

\begin{tabular}{cccc}
\hline Sample & $\mathbf{S}_{\text {BET }}\left(\mathbf{m}^{\mathbf{2}} \mathbf{g}^{\mathbf{- 1}}\right)$ & $\begin{array}{c}\text { Pore Volume } \\
\left(\mathbf{c m}^{\mathbf{3}} \mathbf{g}^{\mathbf{- 1}}\right)\end{array}$ & $\begin{array}{c}\text { Pore Size } \\
(\mathbf{n m})\end{array}$ \\
\hline $0.1 \mathrm{wt} \% \mathrm{~g}_{-} \mathrm{C}_{3} \mathrm{~N}_{4} / \mathrm{BiVO}_{4}$ & 1.89 & 0.005 & 11.37 \\
$0.4 \mathrm{wt} \% \mathrm{~g}-\mathrm{C}_{3} \mathrm{~N}_{4} / \mathrm{BiVO}_{4}$ & 3.25 & 0.019 & 23.37 \\
$0.8 \mathrm{wt} \% \mathrm{~g}_{-} \mathrm{C}_{3} \mathrm{~N}_{4} / \mathrm{BiVO}_{4}$ & 5.31 & 0.029 & 22.03 \\
$1.2 \mathrm{wt} \% \mathrm{~g}_{-} \mathrm{C}_{3} \mathrm{~N}_{4} / \mathrm{BiVO}_{4}$ & 4.09 & 0.022 & 22.10 \\
\hline
\end{tabular}

According to the IUPAC classification, all of the composite $g-\mathrm{C}_{3} \mathrm{~N}_{4} / \mathrm{BiVO}_{4}$ microflower photocatalysts possesses the type IV isotherms with $\mathrm{H} 3$-type hysteresis loop $\left(\mathrm{P} / \mathrm{P}_{0}>0.4\right) .{ }^{35}$ When the amount of $\mathrm{g}-\mathrm{C}_{3} \mathrm{~N}_{4}$ loading increases, the hysteresis loops area become larger and shift to the lower zone of $\mathrm{P} / \mathrm{P}_{0}$ signifying the formation of enlarged mesopores. ${ }^{43}$ Gratifyingly, the pore size analysis of the composite samples results in the range of $11-23 \mathrm{~nm}$, confirming the predominantly mesoporous structure $(2 \mathrm{~nm}<$ IUPAC pore size $<50 \mathrm{~nm})$ with aggregates of plate-like particles. ${ }^{22}$ As summarized in Table 1, the $0.8 \mathrm{wt} . \% \mathrm{~g}-\mathrm{C}_{3} \mathrm{~N}_{4} / \mathrm{BiVO}_{4}$ sample possesses the highest BET surface area which was likely to result in higher active reaction sites and will be benefited for the photocatalytic activity. 

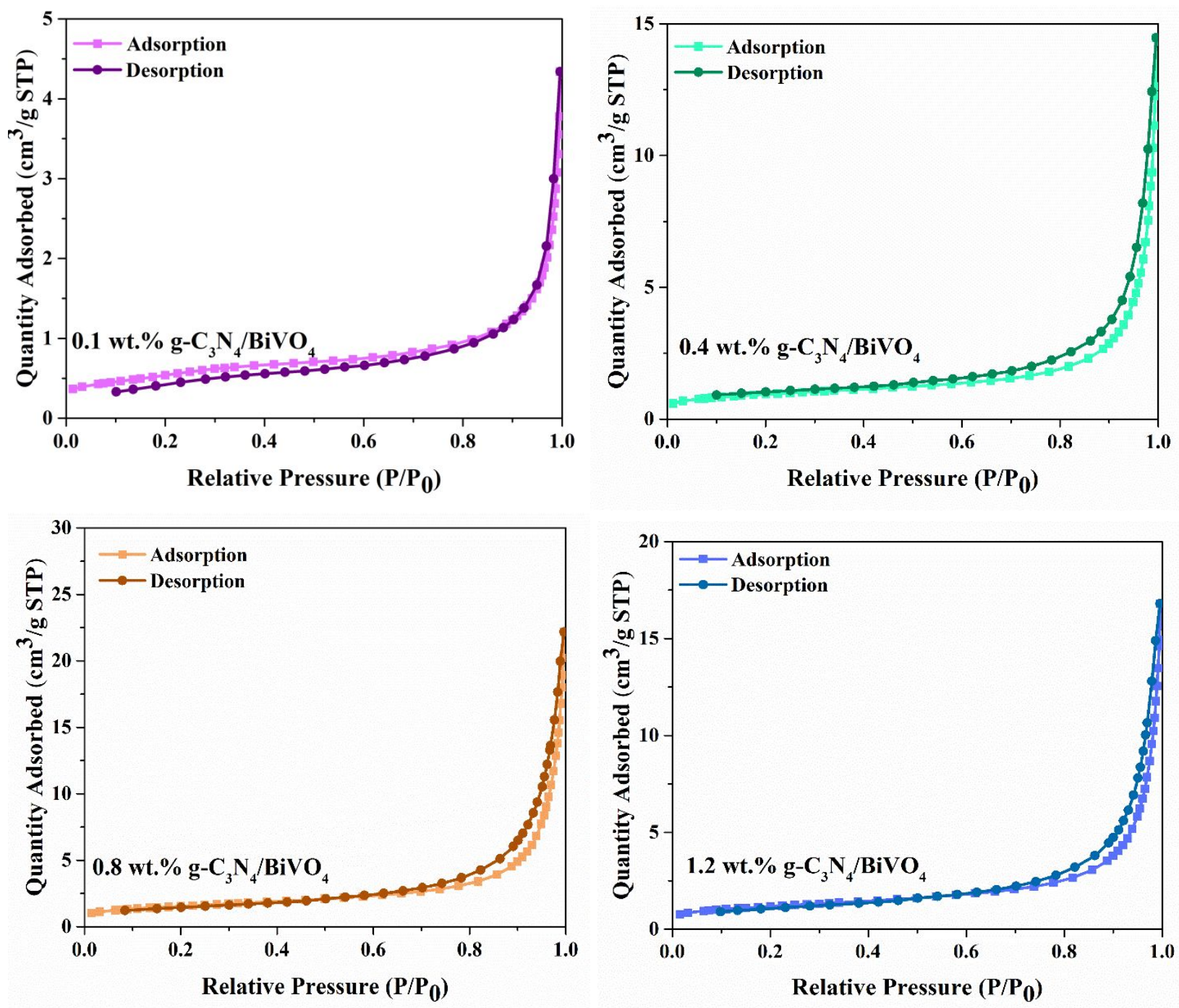

Figure 6: $\mathrm{N}_{2}$ adsorption-desorption isotherms of the $\mathrm{g}-\mathrm{C}_{3} \mathrm{~N}_{4} / \mathrm{BiVO}_{4}$ microflower samples.

\section{Chemical Stability Analysis}

Figure 7 delineated the FTIR spectra of the composite microflower samples. The strong and small shoulder peaks at 760 and $620 \mathrm{~cm}^{-1}$, corresponding to the $v_{3}$ and $v_{4}$ asymmetric stretching vibration of the $\mathrm{Bi}-\mathrm{V}$ and $\mathrm{VO}_{4}{ }^{3-}$, respectively. ${ }^{25}$ Moreover, the wide and sharp peaks at 3042 and $1623 \mathrm{~cm}^{-1}$ corresponding to the adsorbed water molecule and stretching vibration of the combined water molecule, respectively. ${ }^{44}$ Meanwhile, the multi-sharp peaks monitored at 1026, 1232 , and 
$1454 \mathrm{~cm}^{-1}$ correspond to the typical stretching of $\mathrm{C}-\mathrm{N}$ aromatic skeletal and $\mathrm{C}=\mathrm{N}$ stretching vibration modes. ${ }^{45-47}$ The detection of these two peaks will be beneficial for the photoelectrocatalytic activity due to its $\pi$ structure. ${ }^{48}$ Additionally, the presence of all $\mathrm{BiVO}_{4}$ and g- $\mathrm{C}_{3} \mathrm{~N}_{4}$ FTIR peaks footprint signifies the successful synthesis of the as-developed composite, using the hydrothermal method.

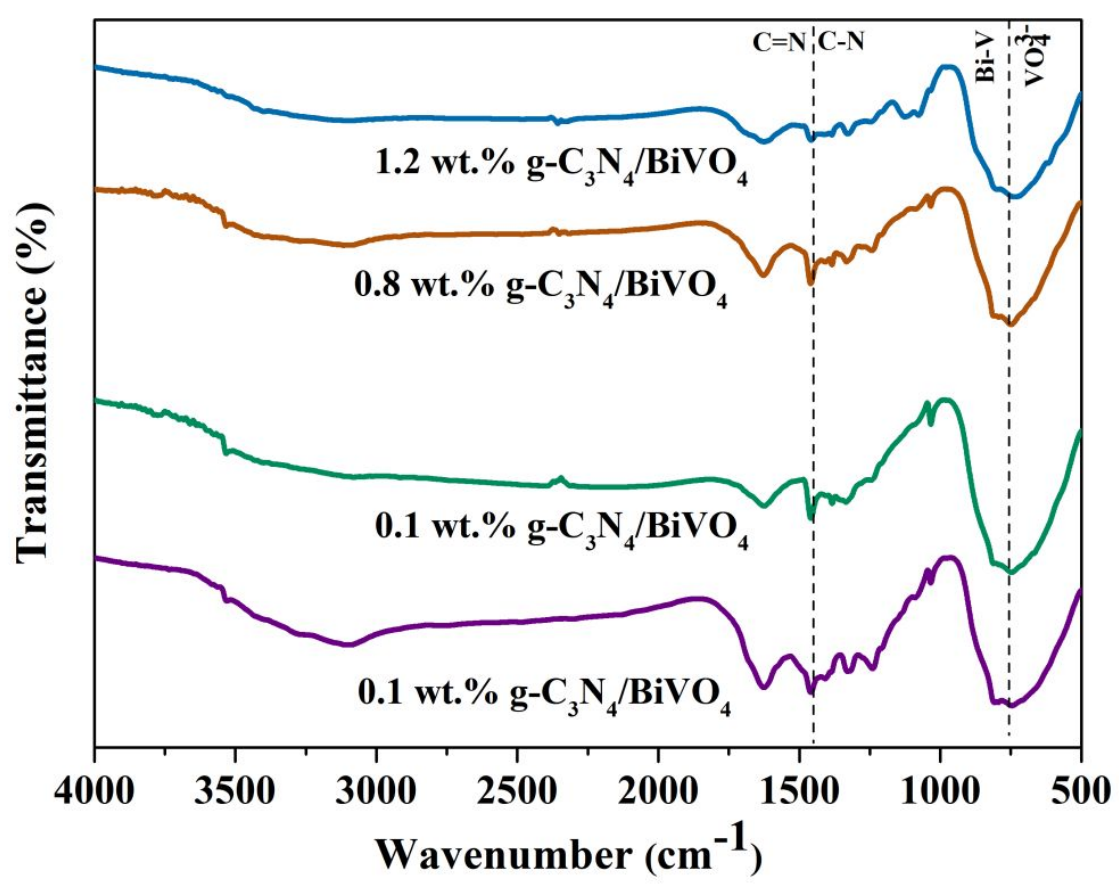

Figure 7: FTIR spectra of the g- $\mathrm{C}_{3} \mathrm{~N}_{4} / \mathrm{BiVO}_{4}$ microflower samples.

\section{Photoelectrochemical Hydrogen Production}

Figure 8 disclosed the photoelectrochemical hydrogen production performance via the asdeveloped composite g- $\mathrm{C}_{3} \mathrm{~N}_{4} / \mathrm{BiVO}_{4}$ microflower photocatalysts which were evaluated using lake water without the addition of any sacrificial reagent. 


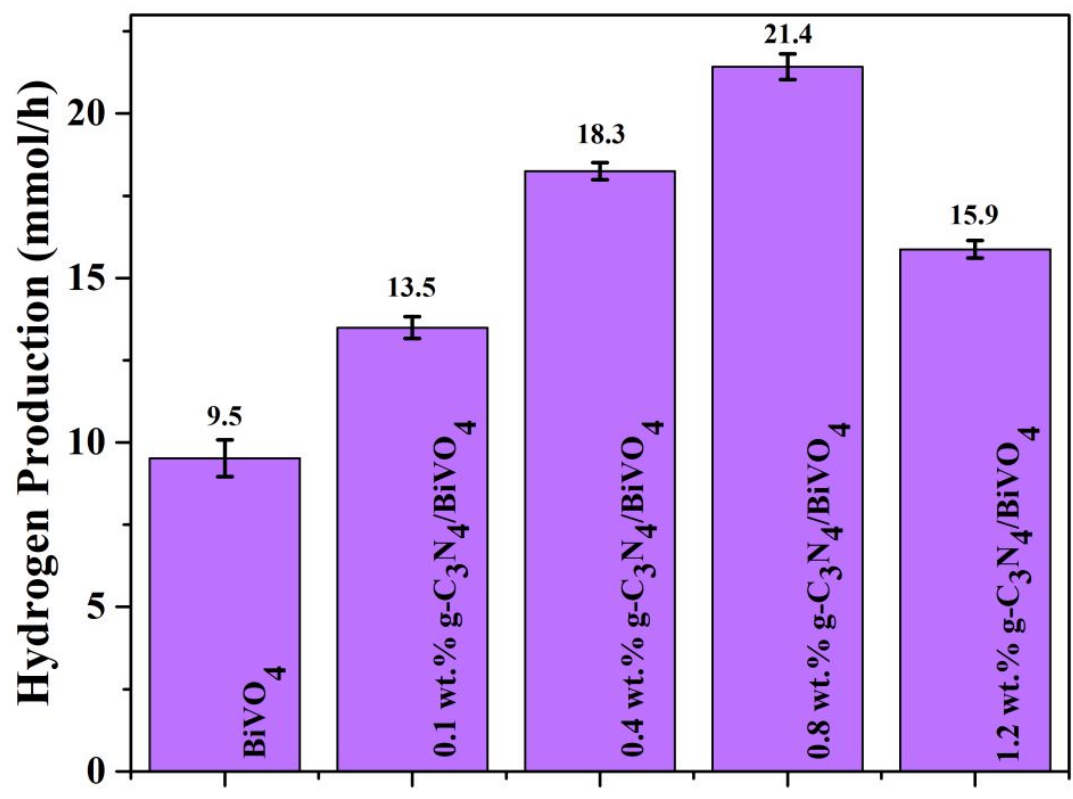

Natural Lake Water

Figure 8: Photoelectrocatalytic hydrogen performance of the $\mathrm{g}-\mathrm{C}_{3} \mathrm{~N}_{4} / \mathrm{BiVO}_{4}$ microflower samples.

The pure $3 \mathrm{D} \mathrm{BiVO}_{4}$ sample possesses a limited hydrogen production performance $(9.5$ $\mathrm{mmol} / \mathrm{h}$ ), whose hydrogen performance was the lowest compared to the other as-developed samples. Similarly, the pure $\mathrm{g}-\mathrm{C}_{3} \mathrm{~N}_{4}$ was only able to generate $11.9 \mathrm{mmol} / \mathrm{h}$ of hydrogen. The limited hydrogen performance monitored here was due to the natural limitation that exists within the individual pure samples such as short holes diffusion length and photocorrosion wherefore hampered the overall photoelectrocatalytic performance. On the other hand, the composite g$\mathrm{C}_{3} \mathrm{~N}_{4} / \mathrm{BiVO}_{4}$ microflower photocatalysts show promising performance than the pure samples, signifying the smooth photocharge carrier transfer that occurred at the heterostructure interface between the couple photocatalyst due to minimum photocharge resistance. The photoelectrocatalytic hydrogen performance was gradually enhanced up to $0.8 \mathrm{wt} . \%$ amount of g$\mathrm{C}_{3} \mathrm{~N}_{4}$ loading and then slightly decreased with further increase in the amount of $\mathrm{g}-\mathrm{C}_{3} \mathrm{~N}_{4}$ loading. 
This limited photoelectrocatalytic performance observed was presumably originated from the overloading and agglomeration of $\mathrm{g}_{-} \mathrm{C}_{3} \mathrm{~N}_{4}$ particles which covered the $\mathrm{BiVO}_{4}$ photoactive sites, evidently from the FESEM micrograph images as shown in Figure 4. As the light absorption capacity was shielded (see Figure 5), the availability of the photocharge carriers to initiate the photoelectrocatalytic reaction was limited and thus deteriorates the overall photocatalytic performance.

On the contrary, the 0.8 wt. $\%$ g- $\mathrm{C}_{3} \mathrm{~N}_{4} / \mathrm{BiVO}_{4}$ sample yields the significant accumulated of hydrogen evolution with $21.4 \mathrm{mmol} / \mathrm{h}$ in comparison to the other samples. Therefore, it is safe to say that the optimum amount of $\mathrm{g}-\mathrm{C}_{3} \mathrm{~N}_{4}$ loading needed to construct a highly efficient composite microflower photocatalyst was $0.8 \mathrm{wt} . \%$. This is due to the highest BET surface area obtained by 0.8 wt. $\% \mathrm{~g}_{-} \mathrm{C}_{3} \mathrm{~N}_{4} / \mathrm{BiVO}_{4}$ sample as shown in Figure 6 which provides more active site traits in the composite sample and thus more available photocharge carriers can partake in the photocatalytic reaction. In addition, the 0.8 wt.\% $\quad \mathrm{g}_{-} \mathrm{C}_{3} \mathrm{~N}_{4} / \mathrm{BiVO}_{4}$ sample was further evaluated in photoelectrocatalytic hydrogen production using different sources of water, namely deionized water and a mixture of deionized water with $10 \mathrm{vol} . \%$ of $\mathrm{Na}_{2} \mathrm{SO}_{3}$ as a sacrificial reagent. The 0.8 wt.\% g- $\mathrm{C}_{3} \mathrm{~N}_{4} / \mathrm{BiVO}_{4}$ sample shows a slightly higher accumulated hydrogen evolution in deionized water aqueous media in comparison to the lake water. Moreover, Figure S6 illustrated that the presence of sacrificial reagent in deionized water significantly enhanced the hydrogen evolution. Although the difference in $\mathrm{pH}$ between both water sources was insignificant, the slight enhancement in hydrogen production using deionized water was presumably due to the difference in the miscibility of the as-developed photocatalyst in different water media. In addition, the presence of higher content of organic matter in the lake water can slightly affect the photoelectrocatalytic reaction. The higher content of organic matter in lake water, instead of act as 
a hole scavenger, organic matter can be deposited on the surface of photocatalyst as it is hard to mineralize, consequently limits the overall performance.

The AQE of the as-developed composite $\mathrm{g}-\mathrm{C}_{3} \mathrm{~N}_{4} / \mathrm{BiVO}_{4}$ microflower photocatalysts at 420 $\mathrm{nm}$ was calculated and summarized in Table S2. The 0.8 wt. $\%$ g- $\mathrm{C}_{3} \mathrm{~N}_{4} / \mathrm{BiVO}_{4}$ photocatalysts exhibit the highest AQE $(4.27 \%$ at $420 \mathrm{~nm})$. This calculated AQE can be regarded as one of the highest $\mathrm{AQE}$ in comparison to the current literature. For instance, Bhunia et al. ${ }^{32}$ performed the study on the PtAu- $2 / \mathrm{g}-\mathrm{C}_{3} \mathrm{~N}_{4}$ sample in which they found that this sample attained an AQE of $0.45 \%$ at $420 \mathrm{~nm}$. Meanwhile, an AQE of $1.8 \%$ at $420 \mathrm{~nm}$ was reported by Sun et al. ${ }^{49}$ through their $\mathrm{Pt} / \mathrm{Ni}(\mathrm{OH})_{2}-\mathrm{C}_{3} \mathrm{~N}_{4}$ sample. In addition, Liu et al. ${ }^{50}$ suggest that their $\mathrm{NiO} / \mathrm{CDs} / \mathrm{BiVO}_{4}$ samples obtained an AQE of $1.24 \%$ at $420 \mathrm{~nm}$.

\section{Photoelectrochemical (PEC) Behaviour Analysis}

The photocharge carrier transfer behavior of the as-developed photocatalysts was explored using EIS analysis. It is generally known that the arc radii at the higher frequency indicate the higher electron transport resistance while the arc radii at the lower frequency indicate a smaller resistance for the electron transport. ${ }^{51}$ Interestingly, the semicircle arc diameter of the $0.8 \mathrm{wt} . \% \mathrm{~g}-$ $\mathrm{C}_{3} \mathrm{~N}_{4} / \mathrm{BiVO}_{4}$ sample was the smallest than the other as-developed samples, indicating the smallest electron resistance possesses by this sample, results in the better photocharge carrier separation and migration (see Figure 9). Conversely, the 0.1 wt. $\%$ g- $\mathrm{C}_{3} \mathrm{~N}_{4} / \mathrm{BiVO}_{4}$ sample shows the biggest semicircle arc diameter at a higher frequency, signifying that the rough electron transport mobility in which justifying the limited photoelectrocatalytic hydrogen production observed as shown in Figure 8. Additionally, this data demonstrated that the overloading of the $g-\mathrm{C}_{3} \mathrm{~N}_{4}$ particles would 
result in the blockage of the active site and upsurge the photocharge carrier resistance and thus deteriorating the photoelectrocatalytic activity as indicated by $1.2 \mathrm{wt} . \% \mathrm{~g}-\mathrm{C}_{3} \mathrm{~N}_{4} / \mathrm{BiVO}_{4}$ sample.

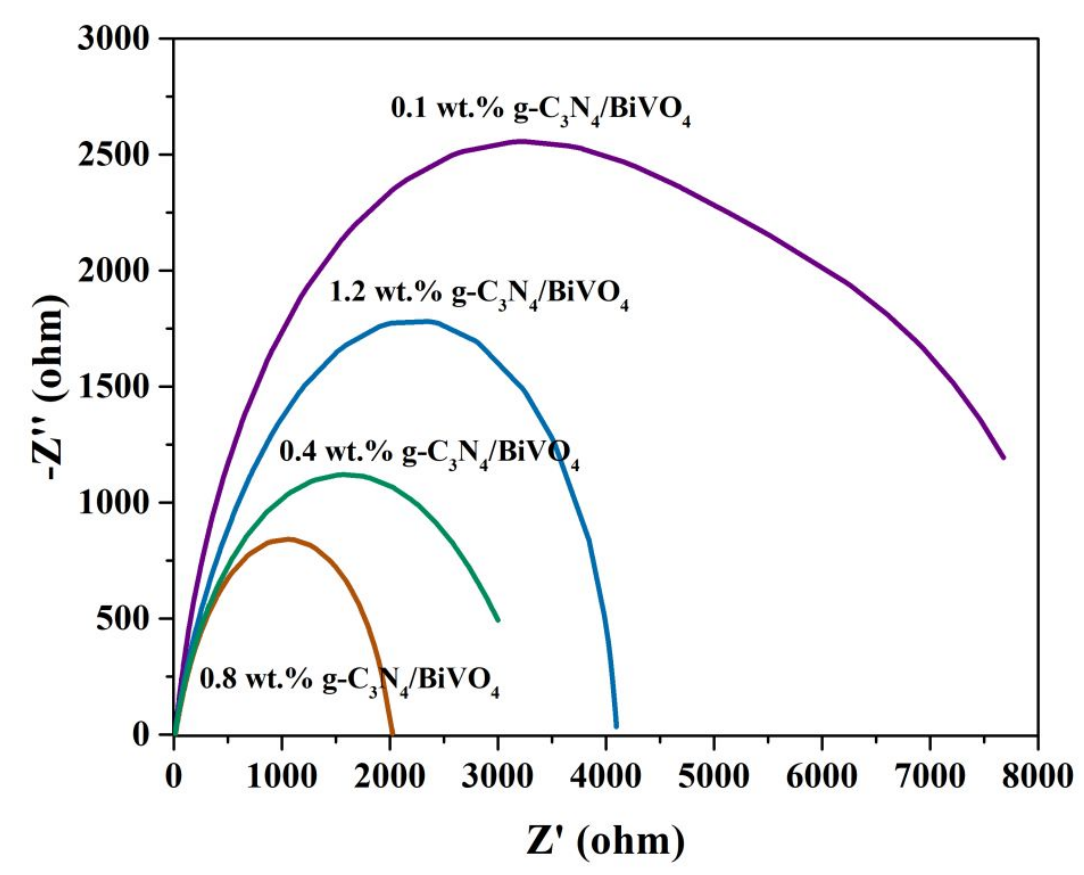

Figure 9: EIS analysis of the $\mathrm{g}-\mathrm{C}_{3} \mathrm{~N}_{4} / \mathrm{BiVO}_{4}$ microflower samples.

The current-potential (I-V) curve was plotted according to the Linear Sweep Voltammogram (LSV) which was recorded under visible light illumination. Figure 10 reveals that the 0.8 wt.\% g$\mathrm{C}_{3} \mathrm{~N}_{4} / \mathrm{BiVO}_{4}$ photocatalyst yields the highest photocurrent density of $9.68 \mathrm{~mA} / \mathrm{cm}^{2}$ at $1.0 \mathrm{~V}$ vs $\mathrm{Ag} / \mathrm{AgCl}$ while the $0.1 \mathrm{wt} . \% \mathrm{~g}-\mathrm{C}_{3} \mathrm{~N}_{4} / \mathrm{BiVO}_{4}$ sample shows the lowest photocurrent density of 1.01 $\mathrm{mA} / \mathrm{cm}^{2}$ at $1.0 \mathrm{~V}$ vs $\mathrm{Ag} / \mathrm{AgCl}$. The overloading of the $\mathrm{g}-\mathrm{C}_{3} \mathrm{~N}_{4}$ particle would result in the deteriorating performance as shown by the limited photocurrent density of $1.2 \mathrm{wt} . \% \mathrm{~g}-\mathrm{C}_{3} \mathrm{~N}_{4} / \mathrm{BiVO}_{4}$ sample. The overloading of the particles might result in the blockage of the light absorption capacity and heightened the photocharge transfer resistance. Hence, a limited amount of the 
photocharge carriers being generated for the reaction, consequently affect the overall photoelectrocatalytic performance. ${ }^{18}$

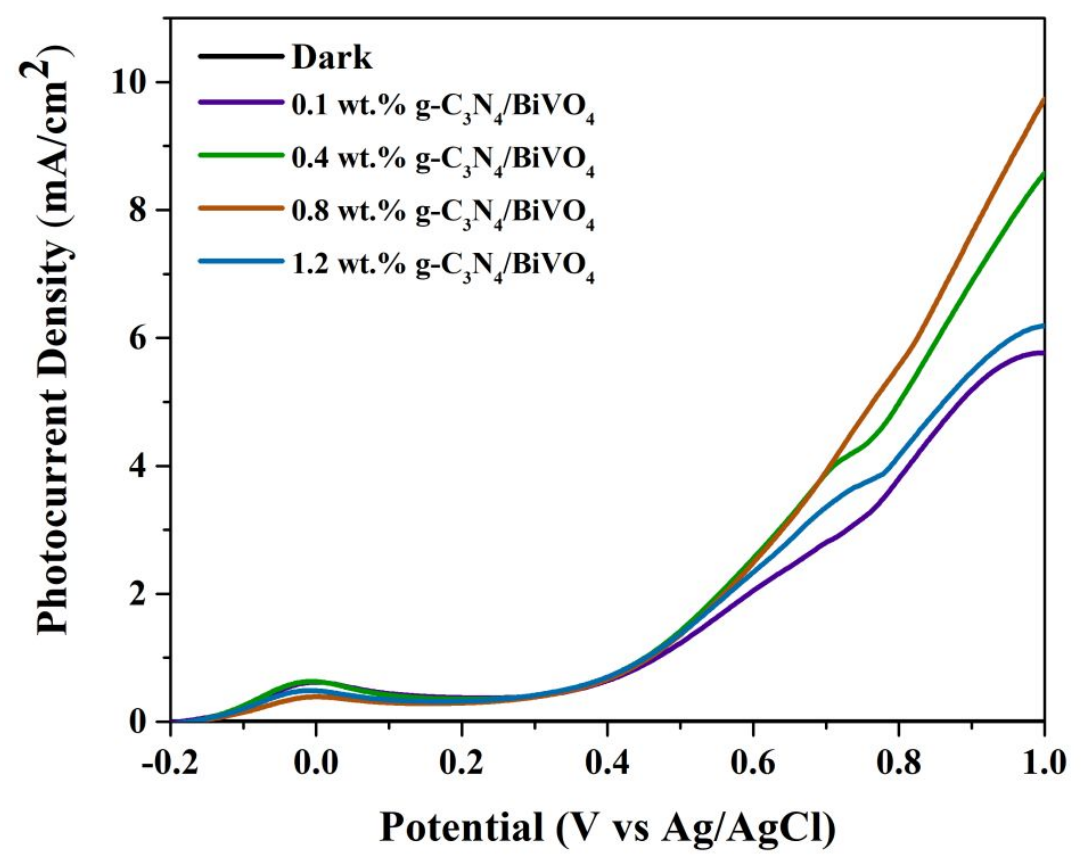

Figure 10: I-V curves of the $\mathrm{g}-\mathrm{C}_{3} \mathrm{~N}_{4} / \mathrm{BiVO}_{4}$ microflower samples.

The efficiencies of the as-developed photocatalysts were further analyzed using applied bias photon conversion efficiency. The details of this calculation have been reported previously. ${ }^{27}$ The maximum photoconversion efficiency obtained via $0.8 \mathrm{wt} . \% \mathrm{~g}-\mathrm{C}_{3} \mathrm{~N}_{4} / \mathrm{BiVO}_{4}$ sample was $0.29 \%$ at $-0.02 \mathrm{~V}$ vs. $\mathrm{Ag} / \mathrm{AgCl}$ electrode. Meanwhile, the $0.1 \mathrm{wt} . \% \mathrm{~g}-\mathrm{C}_{3} \mathrm{~N}_{4} / \mathrm{BiVO}_{4}$ sample shows the limited photoconversion efficiency of $0.17 \%$ at $-0.02 \mathrm{~V}$ vs. $\mathrm{Ag} / \mathrm{AgCl}$ electrode. Interestingly, the composite samples have better photoconversion efficiency than $\mathrm{BiVO}_{4}$ sample (see Figure 11). ${ }^{25}$ This signifies the beneficial effect of the $\mathrm{g}-\mathrm{C}_{3} \mathrm{~N}_{4} / \mathrm{BiVO}$ heterostructure system which was capable of mitigating the existing limitation faced by the pure samples and yield better 
photoelectrocatalytic activity. Concomitant with this, the decrease of the photoconversion efficiency was monitored for 1.2 wt. $\%$ g- $\mathrm{C}_{3} \mathrm{~N}_{4} / \mathrm{BiVO}_{4}$ sample which presumably due to the large electron transport resistance and the agglomeration of the particle, as being discussed previously.

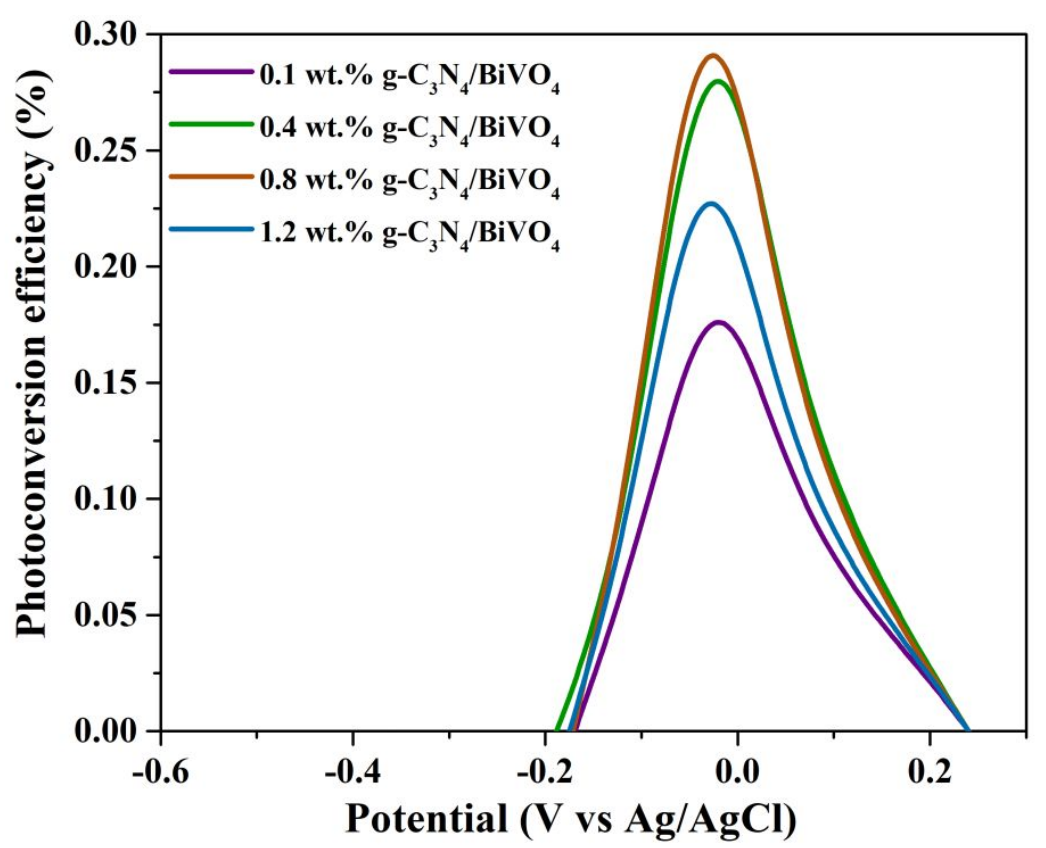

Figure 11: Photoconversion efficiency of the g- $\mathrm{C}_{3} \mathrm{~N}_{4} / \mathrm{BiVO}_{4}$ microflower samples.

\section{Reusability and Recyclability Analysis}

The best photocatalyst sample $\left(0.8\right.$ wt. $\% \mathrm{~g}_{-} \mathrm{C}_{3} \mathrm{~N}_{4} / \mathrm{BiVO}_{4}$ sample $)$ was further investigated relative to its reusability and recyclability features by repeating the reaction for three cyclic activities. For each cycle, the sample was collected and washed prior to the photoelectrocatalytic reaction. 

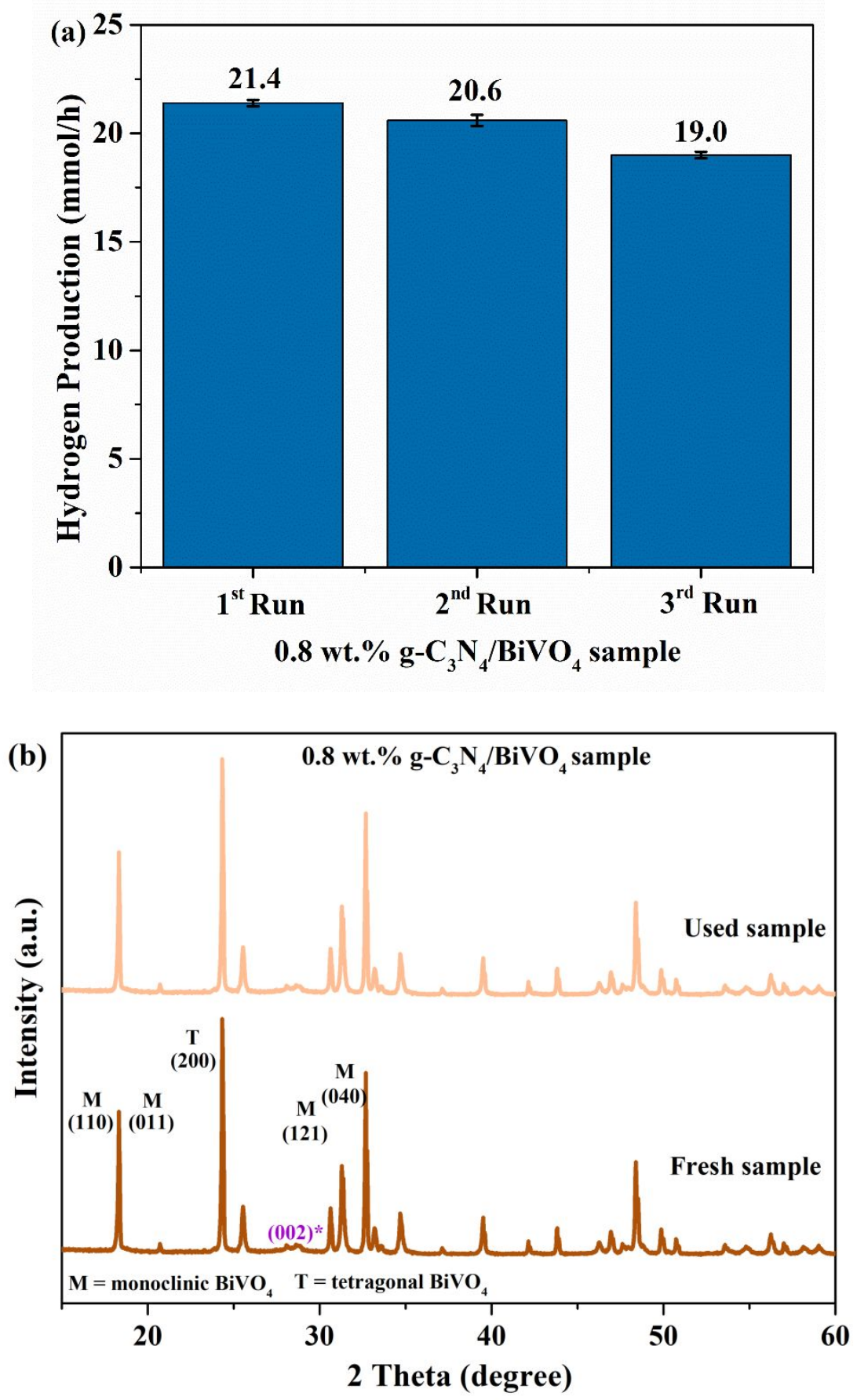

Figure 12: (a) recyclability and reusability study and (b) XRD analysis of the fresh and used 0.8 wt. $\%$ g- $\mathrm{C}_{3} \mathrm{~N}_{4} / \mathrm{BiVO}_{4}$ sample. 
Figure 12 (a) shows that the $0.8 \mathrm{wt} . \% \mathrm{~g}-\mathrm{C}_{3} \mathrm{~N}_{4} / \mathrm{BiVO}_{4}$ sample remains stable even after three cyclic activity with only minimal decreased in photoelectrocatalytic hydrogen production. The slight decrease observed can be due to the potential loss of the original amount of the sample during the restoration and washing process of the recyclability analysis. Correspondingly, there is a potential of slight deactivation and saturation of the active sites which slightly affect the hydrogen production. ${ }^{14,52}$ Additionally, the XRD analysis of the used 0.8 wt. $\%$ g- $\mathrm{C}_{3} \mathrm{~N}_{4} / \mathrm{BiVO}_{4}$ sample after three cyclic activity had almost no obvious discrepancy compared to the used sample, indicating good stability of the aforementioned sample. The obtained results suggest that the asdeveloped composite microflower photocatalyst possesses a strong photostability against photocorrosion in which it will be a good feature for industrial practical application.

\section{Density Functional Theory Analysis}

In order to countercheck the obtained experimental results, periodic DFT analysis was executed. As discussed elsewhere, ${ }^{17-19} \mathrm{BiVO}_{4}$ along (001) direction was very stable and nonpolar. This is stemming from its well-defined surface formation energy $\left(1.95 \mathrm{~J} / \mathrm{m}^{2}\right)$. Figure $\mathrm{S} 1$ demonstrated that the lattice mismatch of the designed $\mathrm{g}-\mathrm{C}_{3} \mathrm{~N}_{4} / \mathrm{BiVO}_{4}$ heterojunction was about $0.02 \%$. Moreover, an adequate vacuum region was imposed in this heterostructure DFT analysis to attenuate the systems contagious interaction. There were three non-covalent type interactions were found within the composite systems which were stemming from the $\mathrm{Bi}-\mathrm{N}, \mathrm{O}-\mathrm{C}$, and $\mathrm{O}-\mathrm{N}$ bonding. The total inter-bonding energy of this heterojunction was about $-0.68 \mathrm{eV}$. This adsorption energy reveals a strong electrostatic interaction between coupled photocatalyst in the composite heterojunction. The calculation details on the interaction energy (adsorption) can be found in the SI. 
The obtained experimental results were further compared with the computational band structure and the density of states of the composite microflower photocatalyst. The simulated band structures of parental photocatalyst and composite samples were depicted in Figure S2. An indirect bandgap of $\mathrm{BiVO}_{4}(2.46 \mathrm{eV})$ was simulated and it was found that the indirect bandgap possesses substantial correlation with the computational bandgap (vide supra). Similarly, an indirect bandgap of $\mathrm{g}-\mathrm{C}_{3} \mathrm{~N}_{4}(2.70 \mathrm{eV})$ was simulated and the VBM was positioned at $\Gamma$ and $\mathrm{CBM}$ at $\mathrm{C}$ point as depicted in Figure S2. Finally, the composite microflower sample exhibited indirect bandgap energy of $2.46 \mathrm{eV}$ with an observed position of VBM and CBM at -6.16 and $-3.70 \mathrm{eV}$ (vs. vacuum), respectively. The details on the VBM and CBM of each studied sample have been summarized in Table S1. Interestingly, there are some articulation of flat bands were observed at the VB of the composite microflower sample. The formations of these flat bands within the composite system are beneficial as they can act as hole trapping centres. Thus, this observation was well aligned with the experimental data in which an exceptional photoelectrocatalytic activity and high charge carrier mobilities were observed (refer Figure 8). Correspondingly, the $\mathrm{C}$ and $\mathrm{N}$ atoms of $\mathrm{g}-\mathrm{C}_{3} \mathrm{~N}_{4}$ in $\mathrm{C}_{3} \mathrm{~N}_{4} / \mathrm{BiVO}_{4}$ heterojunction were responsible for these flat bands as can be seen from the DOS (see Figure S3). This statement also validates and confirms the experimental results (vide supra). Moreover, a detailed discussion of the individual atom which forms the VB and CB of the studied photocatalyst can be found in the SI. Similarly, the details calculation of the band alignment and Fermi energy level as illustrated in Figure 13 were included in the SI. It can be concluded that the band edge position of the VBM and CBM for the composite microflower photocatalyst were lower and higher than the theoretical redox potential of water, respectively. 


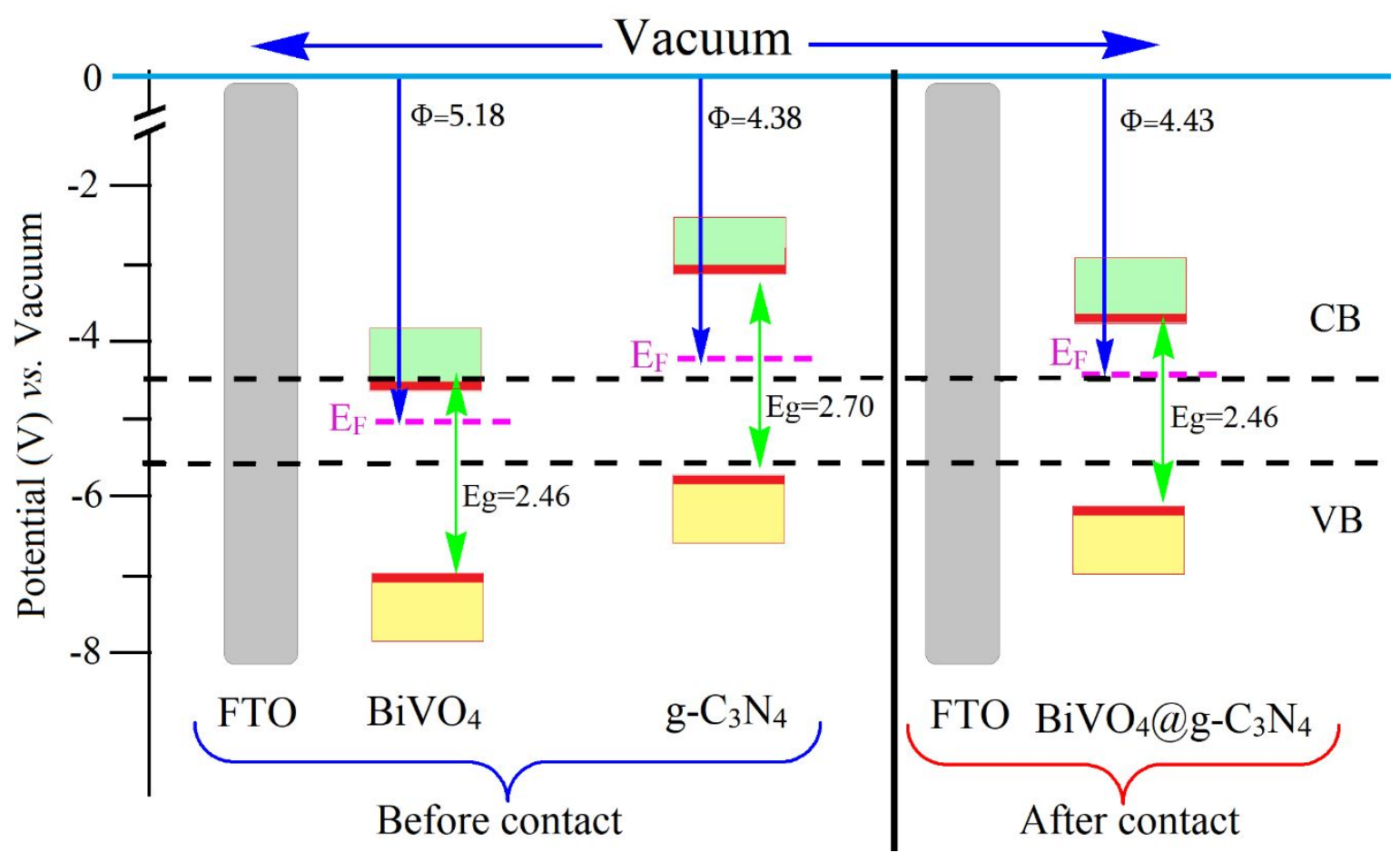

Figure 13: Simulated energy level illustration of the $\mathrm{g}-\mathrm{C}_{3} \mathrm{~N}_{4} / \mathrm{BiVO}_{4}$ microflower sample. All these energies are calculated at vacuum level, where the work functions are also shown.

Furthermore, the electrostatic potentials maps of each studied photocatalysts were shown in Figure S4. The correspondence work function for each sample was summarized in Table S1. Based on Figure S4, there is strong evidence of the inter-charge transferring phenomena occurring within the composite system. The work function of the $\mathrm{BiVO}_{4}$ was found to be above than its coupled photocatalyst, indicating that the inter-charge transferring pathway occurred from the $g-\mathrm{C}_{3} \mathrm{~N}_{4}$ to $\mathrm{BiVO}_{4}$, until the Fermi energy of these species was coordinated. Additionally, the simulated analysis revealed that the VBM and $\mathrm{CBM}$ of the individual $\mathrm{BiVO}_{4}$ were -7.03 and $-4.57 \mathrm{eV}$. Meanwhile, the VBM and $\mathrm{CBM}$ of the individual $\mathrm{g}-\mathrm{C}_{3} \mathrm{~N}_{4}$ were -5.47 and $-3.07 \mathrm{eV}$, respectively. However, when the composite heterostructure system was formed, the VBM and CBM of the composite were found to be in between the band edge location of the pure samples. The band edge 

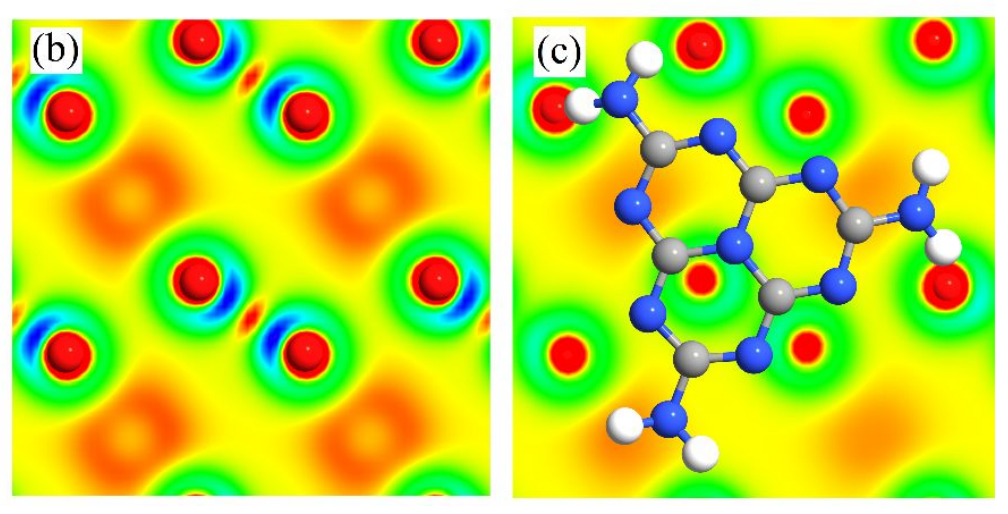

position of the heterostructure system was shifted to an ideal position, results in a narrow bandgap as shown in Figure 13. This observation exemplifies the emerging of an internal electric field and band offset in the composite system which was responsible for enhancing the available photocharge carriers in the system. In addition, this effect will allow a smooth photocharge carrier transfer at the heterostructure interface and thus minimizing the recombination of the photocharge carrier.

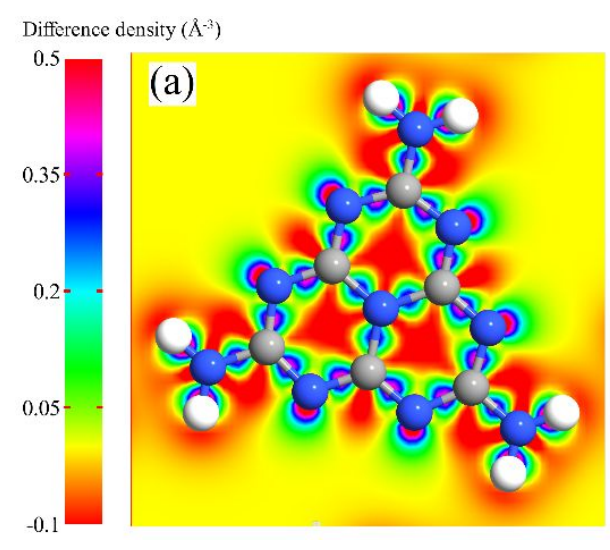

Figure 14: Top view of electron difference density of (a) $\mathrm{g}-\mathrm{C}_{3} \mathrm{~N}_{4}$, (b) $\mathrm{BiVO}_{4}$ and (c) g$\mathrm{C}_{3} \mathrm{~N}_{4} @ \mathrm{BiVO}_{4}$.

On the other hand, Figure 14 and Figure S5 epitomized the electron difference density of the photocatalysts based on the charge density difference (CDD) analysis. It can be seen that both of the pure photocatalysts uphold a delocalized charge distribution. However, in the composite system, the g- $\mathrm{C}_{3} \mathrm{~N}_{4}$ loses its electronic cloud density toward $\mathrm{BiVO}_{4}$. Meanwhile, the observed charge transferring at the composite heterostructure interface was estimated to be 0.056 electrons. Moreover, the observation at the composite system charge redistribution manifests that the reduction and oxidation process occur at the $\mathrm{CB}$ of the $\mathrm{g}-\mathrm{C}_{3} \mathrm{~N}_{4}$ and $\mathrm{VB}$ of the $\mathrm{BiVO}_{4}$, respectively. Meanwhile, the available holes at the VB of the $g_{-} \mathrm{C}_{3} \mathrm{~N}_{4}$ will interact with the neighbouring 
electrons stemming from the $\mathrm{CB}$ of the $\mathrm{BiVO}_{4}$. This pattern of the photocharge carrier pathways emblematized the potential of the Z-scheme system (See Figure S5). As a result, it can be assumed that the composite microflower photocatalyst subsumed a weak Vander Waal type interaction which is an archetype of the p-n junction..$^{53}$

\section{Conclusion}

The $\mathrm{g}-\mathrm{C}_{3} \mathrm{~N}_{4} / \mathrm{BiVO}_{4}$ microflower photocatalysts were synthesized and evaluated using lake water and without the addition of any sacrificial reagent. The composite microflower photocatalysts show an augmented enhancement in the photoelectrocatalytic performance. This enhancement was attributed to the emerging of an internal electric field and band offset which was responsible for heightened the available photocharge carriers in the system. In addition, this effect will allow a smooth photocharge carrier transfer at the heterostructure interface and thus minimizing the recombination of the photocharge carrier. The experimental results were well correlating with the computational density functional theory simulations, in which confirming and validating our data. Moreover, this work serves as a great approach to design highly efficient composite photocatalyst which can facilitate the readiness of this system toward industrialized hydrogen fuels.

\section{ASSOCIATED CONTENT}

Supporting Information is available free of charge via the Internet at http://pubs.acs.org. The content available in this supporting information are the optimized crystal structure, band structures, partial density of states, electrostatic potential maps, and calculation of the apparent quantum efficiency (AQE). 


\section{Acknowledgement}

This work was supported by the Murata Science Foundation Grant (015ME0-033), and the Yayasan Universiti Teknologi PETRONAS (015LC0-138 \& 015LC0-037). The authors also acknowledge the support from the Chemical Engineering Department (UTP) and Centre of Innovative Nanostructures \& Nanodevices (COINN), UTP for the research facilities.

\section{References}

(1) Samsudin, M. F. R.; Dumas, A.; Bashiri, R.; Muti, N. M.; Sufian, S. Development of the g-

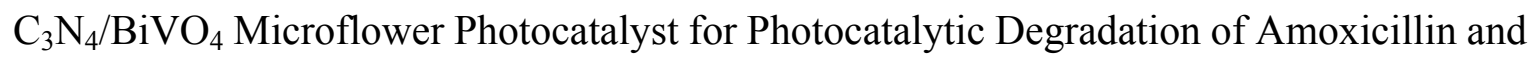
Hydrogen Production. Malaysian J. Microsc. 2020, 16 (1), 180-187. DOI: https://malaysianjournalofmicroscopy.org/ojs/index.php/mjm/article/view/454

(2) Ahmad Madzlan, M. K. A.; Samsudin, M. F. R.; Maeght, F.; Goepp, C.; Sufian, S. Enhancement of $\mathrm{g}-\mathrm{C}_{3} \mathrm{~N}_{4}$ via Acid Treatment for the Degradation of Ciprofloxacin Antibiotic. Malaysian J. Microsc. 2020, $16 \quad$ (1), 105-114. DOI: https://malaysianjournalofmicroscopy.org/ojs/index.php/mjm/article/view/447

(3) Saafie, N.; Samsudin, M. F. R.; Sufian, S. Optimization of Methylene Blue Adsorption via Functionalized Activated Carbon Using Response Surface Methodology with Central Composite Design. Key Eng. Mater. 2020, 841, 220-224. DOI: 10.4028/www.scientific.net/KEM.841.220

(4) Tayebi, M.; Lee, B. K. Recent Advances in $\mathrm{BiVO}_{4}$ Semiconductor Materials for Hydrogen Production Using Photoelectrochemical Water Splitting. Renew. Sustain. Energy Rev. 2019, 111 (May), 332-343. DOI: 10.1016/j.rser.2019.05.030

(5) He, Y.; Hamann, T.; Wang, D. Thin Film Photoelectrodes for Solar Water Splitting. Chem. Soc. Rev. 2019, 48, 2182-2215. DOI: 10.1039/c8cs00868j

(6) Meng, S.; Zhang, J.; Chen, S.; Zhang, S.; Huang, W. Perspective on Construction of 
Heterojunction Photocatalysts and the Complete Utilization of Photogenerated Charge Carriers. Appl. Surf. Sci. 2019, 476, 982-992. DOI: 10.1016/j.apsusc.2019.01.246

(7) Alarawi, A.; Ramalingam, V.; He, J. H. Recent Advances in Emerging Single Atom Confined Two-Dimensional Materials for Water Splitting Applications. Mater. Today Energy 2019, 11, 1-23. DOI: 10.1016/j.mtener.2018.10.014

(8) Tan, H. L.; Abdi, F. F.; Ng, Y. H. Heterogeneous Photocatalysts: An Overview of Classic and Modern Approaches for Optical, Electronic, and Charge Dynamics Evaluation. Chem. Soc. Rev. 2019, 48, 1255-1271. DOI: 10.1039/C8CS00882E

(9) Wu, M.; Jing, Q.; Feng, X.; Chen, L. BiVO 4 Microstructures with Various Morphologies: Synthesis and Characterization. Appl. Surf. Sci. 2018, 427 (3), 525-532. DOI: 10.1016/j.apsusc.2017.07.299

(10) Lu, Y.; Shang, H.; Guan, H.; Zhao, Y.; Zhang, H.; Zhang, B. Enhanced Visible-Light Photocatalytic Activity of $\mathrm{BiVO}_{4}$ microstructures via Annealing Process. Superlattices Microstruct. 2015, 88, 591-599. DOI: 10.1016/j.spmi.2015.10.016

(11) Wang, X.; Li, Z.; Shi, J.; Yu, Y. One-Dimensional Titanium Dioxide Nanomaterials: Nanowires, Nanorods, and Nanobelts. Chem. Rev. 2014, 114 (19), 9346-9384. DOI: $10.1021 / \mathrm{cr} 400633 \mathrm{~s}$

(12) Babu, V. J.; Vempati, S.; Uyar, T.; Ramakrishna, S. Review of One-Dimensional and TwoDimensional Nanostructured Materials for Hydrogen Generation. Phys. Chem. Chem. Phys. 2015, 17 (5), 2960-2986. DOI: 10.1039/c4cp04245j

(13) Samsudin, M. F. R.; Bacho, N.; Sufian, S.; Ng, Y. H. Photocatalytic Degradation of Phenol Wastewater over Z-Scheme g- $\mathrm{C}_{3} \mathrm{~N}_{4} / \mathrm{CNT} / \mathrm{BiVO}_{4}$ Heterostructure Photocatalyst under Solar Light Irradiation. J. Mol. Liq. 2019, 277, 977-988. DOI: 10.1016/j.molliq.2018.10.160

(14) Samsudin, M. F. R.; Jayabalan, P. J.; Ong, W. J.; Ng, Y. H.; Sufian, S. Photocatalytic Degradation of Real Industrial Poultry Wastewater via Platinum Decorated $\mathrm{BiVO}_{4} / \mathrm{g}-\mathrm{C}_{3} \mathrm{~N}_{4}$ Photocatalyst under Solar Light Irradiation. J. Photochem. Photobiol. A Chem. 2019, 378, 
46-56. DOI: 10.1016/j.jphotochem.2019.04.013

(15) Samsudin, M. F. R.; Sufian, S.; Hameed, B. H. Epigrammatic Progress and Perspective on the Photocatalytic Properties of $\mathrm{BiVO}_{4}$-Based Photocatalyst in Photocatalytic Water Treatment Technology: A Review. J. Mol. Liq. 2018, 268, 438-459. DOI: 10.1016/j.molliq.2018.07.051

(16) Tan, H. L.; Amal, R.; Ng, Y. H. Alternative Strategies in Improving the Photocatalytic and Photoelectrochemical Activities of Visible Light-Driven $\mathrm{BiVO}_{4}$ : A Review. J. Mater. Chem. A 2017, 5 (32), 16498-16521. DOI: 10.1039/c7ta04441k

(17) Mohamed, N. A.; Ullah, H.; Safaei, J.; Ismail, A. F.; Mohamad Noh, M. F.; Soh, M. F.; Ibrahim, M. A.; Ludin, N. A.; Mat Teridi, M. A. Efficient Photoelectrochemical Performance of $\gamma$ Irradiated g- $\mathrm{C}_{3} \mathrm{~N}_{4}$ and Its g- $\mathrm{C}_{3} \mathrm{~N}_{4} @ \mathrm{BiVO}_{4}$ Heterojunction for Solar Water Splitting. J. Phys. Chem. C 2019, 123 (14), 9013-9026. DOI: 10.1021/acs.jpcc.9b00217

(18) Safaei, J.; Ullah, H.; Mohamed, N. A.; Mohamad Noh, M. F.; Soh, M. F.; Tahir, A. A.; Ahmad Ludin, N.; Ibrahim, M. A.; Wan Isahak, W. N. R.; Mat Teridi, M. A. Enhanced Photoelectrochemical Performance of Z-Scheme g- $\mathrm{C}_{3} \mathrm{~N}_{4} / \mathrm{BiVO}_{4}$ photocatalyst. Appl. Catal. B Environ. 2018, 234, 296-310. DOI: 10.1016/j.apcatb.2018.04.056

(19) Ullah, H.; Tahir, A. A.; Mallick, T. K. Structural and Electronic Properties of Oxygen Defective and Se-Doped p-Type $\mathrm{BiVO}_{4}(001)$ Thin Film for the Applications of Photocatalysis. Appl. Catal. B Environ. 2018, 224, 895-903. DOI: 10.1016/j.apcatb.2017.11.034

(20) Nasir, S. N. F. M.; Ullah, H.; Ebadi, M.; Tahir, A. A.; Sagu, J. S.; Teridi, M. A. M. New Insights into $\mathrm{Se} / \mathrm{BiVO}_{4}$ Heterostructure for Photoelectrochemical Water Splitting: A Combined Experimental and DFT Study. J. Phys. Chem. C 2017, 121 (11), 6218-6228. DOI: $10.1021 /$ acs.jpcc.7b01149

(21) Fu, J.; Xu, Q.; Low, J.; Jiang, C.; Yu, J. Ultrathin 2D/2D WO$/ \mathrm{W}_{3}-\mathrm{C}_{3} \mathrm{~N}_{4}$ Step-Scheme $\mathrm{H}_{2}-$ Production Photocatalyst. Appl. Catal. B Environ. 2019, 243, 556-565. DOI: 10.1016/j.apcatb.2018.11.011 
(22) Reli, M.; Troppová, I.; Šihor, M.; Pavlovský, J.; Praus, P.; Kočí, K. Photocatalytic Decomposition of $\mathrm{N}_{2} \mathrm{O}$ over $\mathrm{g}-\mathrm{C}_{3} \mathrm{~N}_{4} / \mathrm{BiVO}_{4}$ Composite. Appl. Surf. Sci. 2019, 469, 181191. DOI: 10.1016/j.apsusc.2018.10.255

(23) Wang, J.; Liu, C.; Yang, S.; Lin, X.; Shi, W. Fabrication of a Ternary Heterostructure $\mathrm{BiVO}_{4}$ Quantum Dots/C60/g- $\mathrm{C}_{3} \mathrm{~N}_{4}$ Photocatalyst with Enhanced Photocatalytic Activity. J. Phys. Chem. Solids 2020, 136, 109164. DOI: 10.1016/j.apcatb.2017.11.034

(24) Wang, Y.; Tan, G.; Liu, T.; Su, Y.; Ren, H.; Zhang, X. L.; Xia, A.; Lv, L.; Liu, Y. Photocatalytic Properties of the $\mathrm{g}-\mathrm{C}_{3} \mathrm{~N}_{4} /\{010\}$ Facets $\mathrm{BiVO}_{4}$ interface Z-Scheme Photocatalysts Induced by $\mathrm{BiVO}_{4}$ surface Heterojunction. Appl. Catal. B Environ. 2018, 234 , 37-49. DOI: 10.1016/j.apcatb.2018.04.026

(25) Samsudin, M. F. R.; Bashiri, R.; Mohamed, N. M.; Ng, Y. H.; Sufian, S. Tailoring the Morphological Structure of $\mathrm{BiVO}_{4}$ Photocatalyst for Enhanced Photoelectrochemical Solar Hydrogen Production from Natural Lake Water. Appl. Surf. Sci. 2020, 504, 144417. DOI: 10.1016/j.apsusc.2019.144417

(26) Bashiri, R.; Mohamed, N. M.; Fai Kait, C.; Sufian, S.; Khatani, M. Enhanced Hydrogen Production over Incorporated $\mathrm{Cu}$ and $\mathrm{Ni}$ into Titania Photocatalyst in Glycerol-Based Photoelectrochemical Cell: Effect of Total Metal Loading and Calcination Temperature. Int. J. Hydrogen Energy 2017, 42 (15), 9553-9566. DOI: 10.1016/j.ijhydene.2017.01.225

(27) Bashiri, R.; Samsudin, M. F. R.; Mohamed, N. M.; Suhaimi, N. A.; Ling, L. Y.; Sufian, S.; Kait, C. F. Influence of Growth Time on Photoelectrical Characteristics and Photocatalytic Hydrogen Production of Decorated $\mathrm{Fe}_{2} \mathrm{O}_{3}$ on $\mathrm{TiO}_{2}$ Nanorod in Photoelectrochemical Cell. Appl. Surf. Sci. 2020, 510 (1), 327-335. DOI: 10.1016/j.apsusc.2020.145482

(28) Humayun, M.; Ullah, H.; Cao, J.; Pi, W.; Yuan, Y.; Ali, S.; Tahir; A.A.; Yue, P.; Khan, A.; Zheng, Z.; Fu, Q.; Luo, W. Experimental and DFT studies of Au Deposition over $\mathrm{WO}_{3} / \mathrm{g}-$ $\mathrm{C}_{3} \mathrm{~N}_{4}$ Z-Scheme Heterojunction. Nano-Micro Lett. 2020, 12, 7. DOI: 10.1007/s40820-019$0345-2$

(29) Wang, J.; Song, Y.; Hu, J.; Li, Y.; Wang, Z.; Yang, P.; Wang, G.; Ma, Q.; Che, Q.; Dai, Y.; 33 
Huang, B. Photocatalytic Hydrogen Evolution on P-Type Tetragonal Zircon $\mathrm{BiVO}_{4}$. Appl. Catal. B Environ. 2019, 251, 94-101. DOI: 10.1016/j.apcatb.2019.03.049

(30) Baral, B.; Reddy, K. H.; Parida, K. M. Construction of M-BiVO $4 /$ T-BiVO ${ }_{4}$ Isotype Heterojunction for Enhanced Photocatalytic Degradation of Norfloxacine and Oxygen Evolution Reaction. J. Colloid Interface Sci. 2019, 554, 278-295. DOI: 10.1016/j.jcis.2019.07.007

(31) Khan, I.; Baig, N.; Qurashi, A. Graphitic Carbon Nitride Impregnated Niobium Oxide (g$\mathrm{C}_{3} \mathrm{~N}_{4} / \mathrm{Nb}_{2} \mathrm{O}_{5}$ ) Type (II) Heterojunctions and Its Synergetic Solar-Driven Hydrogen Generation. ACS Appl. Energy Mater. 2019, 2 (1), 607-615. DOI:10.1021/acsaem.8b01633

(32) Bhunia, K.; Chandra, M.; Khilari, S.; Pradhan, D. Bimetallic PtAu Alloy NanoparticlesIntegrated g- $\mathrm{C}_{3} \mathrm{~N}_{4}$ Hybrid as an Efficient Photocatalyst for Water-to-Hydrogen Conversion. ACS Appl. Mater. Interfaces 2019, 11 (1), 478-488. DOI: 10.1021/acsami.8b12183

(33) Thomas, A.; Fischer, A.; Goettmann, F.; Antonietti, M.; Müller, J.-O. O.; Schlögl, R.; Carlsson, J. M. Graphitic Carbon Nitride Materials: Variation of Structure and Morphology and Their Use as Metal-Free Catalysts. J. Mater. Chem. 2008, 18 (41), 4893-4908. DOI: 10.1039/B800274F

(34) Liu, T.; Tan, G.; Zhao, C.; Xu, C.; Su, Y.; Wang, Y.; Ren, H.; Xia, A.; Shao, D.; Yan, S. Enhanced Photocatalytic Mechanism of the Nd-Er Co-Doped Tetragonal $\mathrm{BiVO}_{4}$ Photocatalysts. Appl. Catal. B Environ. 2017, 213, 87-96. DOI: 10.1016/j.apcatb.2017.05.018

(35) Jo, W. K.; Natarajan, T. S. Fabrication and Efficient Visible Light Photocatalytic Properties of Novel Zinc Indium Sulfide $\left(\mathrm{ZnIn}_{2} \mathrm{~S}_{4}\right)$ - Graphitic Carbon Nitride $\left(\mathrm{g}^{-} \mathrm{C}_{3} \mathrm{~N}_{4}\right)$ /Bismuth Vanadate $\left(\mathrm{BiVO}_{4}\right)$ Nanorod-Based Ternary Nanocomposites with Enhanced Charge Separation via Z-Scheme Transfer. J. Colloid Interface Sci. 2016, 482, 58-72. DOI: 10.1016/j.jcis.2016.07.062

(36) Ou, M.; Nie, H.; Zhong, Q.; Zhang, S.; Zhong, L. Controllable Synthesis of 3D BiVO Superstructures with Visible-Light-Induced Photocatalytic Oxidation of NO in the Gas 
Phase and Mechanistic Analysis. Phys. Chem. Chem. Phys. 2015, 17 (43), 28809-28817. DOI: $10.1039 / \mathrm{C} 5 \mathrm{CP} 04730 \mathrm{G}$

(37) Gao, H.; Cao, R.; Zhang, S.; Yang, H.; Xu, X. Three-Dimensional Hierarchical g- ${ }_{3} \mathrm{~N}_{4}$ Architectures Assembled by Ultrathin Self-Doped Nanosheets: Extremely Facile Hexamethylenetetramine Activation and Superior Photocatalytic Hydrogen Evolution. ACS Appl. Mater. Interfaces 2019, 11 (2), 2050-2059. DOI: 10.1021/acsami.8b17757

(38) Li, C.; Lou, Z.; Yang, Y.; Wang, Y.; Lu, Y.; Ye, Z.; Zhu, L. Hollowsphere Nanoheterojunction of $\mathrm{g}-\mathrm{C}_{3} \mathrm{~N}_{4} @ \mathrm{TiO}_{2}$ with High Visible Light Photocatalytic Property. Langmuir 2019, 35 (3), 778-786. DOI: 10.1021/acs.langmuir.8b03867

(39) Zalfani, M.; Van Der Schueren, B.; Hu, Z. Y.; Rooke, J. C.; Bourguiga, R.; Wu, M.; Li, Y.; Van Tendeloo, G.; Su, B. L. Novel 3DOM BiVO $4 / \mathrm{TiO}_{2}$ Nanocomposites for Highly Enhanced Photocatalytic Activity. J. Mater. Chem. A 2015, 3 (42), 21244-21256. DOI: $\underline{10.1039 / \mathrm{C} 5 \mathrm{TA00783F}}$

(40) Cui, Y.; Zhang, X.; Zhang, H.; Cheng, Q.; Cheng, X. Construction of BiOCOOH/g- ${ }_{3} \mathrm{~N}_{4}$ composite Photocatalyst and Its Enhanced Visible Light Photocatalytic Degradation of Amido Black 10B. Sep. Purif. Technol. 2019, 210, 125-134. DOI: 10.1016/j.seppur.2018.07.059

(41) Lin, Y.; Lu, C.; Wei, C. Microstructure and Photocatalytic Performance of BiVO Prepared $^{2}$ by Hydrothermal Method. J. Alloys Compd. 2019, 781, 56-63. DOI: 10.1016/j.jallcom.2018.12.071

(42) Samsudin, M. F. R.; Sufian, S.; Mohamed, N. M.; Bashiri, R.; Wolfe, F.; Ramli, R. M. Enhancement of Hydrogen Production over Screen-Printed $\mathrm{TiO}_{2} / \mathrm{BiVO}_{4}$ thin Film in the Photoelectrochemical Cells. Mater. Lett. 2018, 211, 13-16. DOI: 10.1016/j.matlet.2017.09.013

(43) Dong, F.; Wang, Z.; Sun, Y.; Ho, W. K.; Zhang, H. Engineering the Nanoarchitecture and Texture of Polymeric Carbon Nitride Semiconductor for Enhanced Visible Light Photocatalytic Activity. J. Colloid Interface Sci. 2013, 401, 70-79. DOI: 


\subsection{6/j.jcis.2013.03.034}

(44) Sun, R.; Shi, Q.; Zhang, M.; Xie, L.; Chen, J.; Yang, X.; Chen, M.; Zhao, W. Enhanced Photocatalytic Oxidation of Toluene with a Coral-like Direct Z-Scheme $B i V O=/ g-C_{3} \mathrm{~N}_{4}$ photocatalyst. J. Alloys Compd. 2017, 714, 619-626. DOI: 10.1016/j.jallcom.2017.04.108

(45) Ma, J.; Tao, X. Y.; Zhou, S. X.; Song, X. Z.; Lin-Guo; Yao-Wang; Zhu, Y. B.; Guo, L. T.; Liu, Z. S.; Fan, H. L.; Wei, X. Y. Facile Fabrication of Ag/PANI/g-C ${ }_{3} \mathrm{~N}_{4}$ Composite with Enhanced Electrochemical Performance as Supercapacitor Electrode. J. Electroanal. Chem. 2019, 835, 346-353. DOI: 10.1016/j.jelechem.2018.12.025

(46) Kong, H. J.; Won, D. H.; Kim, J.; Woo, S. I. Sulfur-Doped g-C ${ }_{3} \mathrm{~N}_{4} / \mathrm{BiVO}_{4} \mathrm{Composite}$ Photocatalyst for Water Oxidation under Visible Light. Chem. Mater. 2016, 28 (5), 13181324. DOI: 10.1021/acs.chemmater.5b04178

(47) Lee, A. H.; Wang, Y. C.; Chen, C. C. Composite Photocatalyst, Tetragonal Lead Bismuth Oxyiodide/Bismuth Oxyiodide/Graphitic Carbon Nitride: Synthesis, Characterization, and Photocatalytic Activity. J. Colloid Interface Sci. 2019, 533, 319-332. DOI: 10.1016/j.jcis. 2018.08 .008

(48) Cheng, J.; Yan, X.; Mo, Q.; Liu, B.; Wang, J.; Yang, X.; Li, L. Facile Synthesis of g$\mathrm{C}_{3} \mathrm{~N}_{4} / \mathrm{BiVO}_{4}$ Heterojunctions with Enhanced Visible Light Photocatalytic Performance. Ceram. Int. 2017, 43 (1), 301-307. DOI: 10.1016/j.ceramint.2016.09.156

(49) Sun, S.; Zhang, Y. C.; Shen, G.; Wang, Y.; Liu, X.; Duan, Z.; Pan, L.; Zhang, X.; Zou, J. J. Photoinduced Composite of Pt Decorated $\mathrm{Ni}(\mathrm{OH})_{2}$ as Strongly Synergetic Cocatalyst to Boost $\mathrm{H}_{2} \mathrm{O}$ Activation for Photocatalytic Overall Water Splitting. Appl. Catal. B Environ. 2019, 243 (October 2018), 253-261. DOI: 10.1016/j.apcatb.2018.10.051

(50) Liu, C.; Fu, Y.; Zhao, J.; Wang, H.; Huang, H.; Liu, Y.; Dou, Y.; Shao, M.; Kang, Z. AllSolid-State Z-Scheme System of $\mathrm{NiO} / \mathrm{CDs} / \mathrm{BiVO}_{4}$ for Visible Light-Driven Efficient Overall Water Splitting. Chem. Eng. J. 2019, 358, 134-142. DOI: 10.1016/j.cej.2018.10.005 
(51) Wang, F.; Wang, Y.; Feng, Y.; Zeng, Y.; Xie, Z.; Zhang, Q.; Su, Y.; Chen, P.; Liu, Y.; Yao, K.; Lv, W.; Liu, G. Novel Ternary Photocatalyst of Single Atom-Dispersed Silver and Carbon Quantum Dots Co-Loaded with Ultrathin $\mathrm{g}_{-} \mathrm{C}_{3} \mathrm{~N}_{4}$ for Broad Spectrum Photocatalytic Degradation of Naproxen. Appl. Catal. B Environ. 2018, 221, 510-520.DOI: 10.1016/j.apcatb.2017.09.055

(52) Nekouei, F.; Nekouei, S.; Pouzesh, M.; Liu, Y. Porous-CdS/Cu2O/Graphitic- $\mathrm{C}_{3} \mathrm{~N}_{4}$ Dual p$\mathrm{n}$ Junctions as Highly Efficient Photo/Catalysts for Degrading Ciprofloxacin and Generating Hydrogen Using Solar Energy. Chem. Eng. J. 2020, 385, 123710.DOI: 10.1016/j.cej.2019.123710

(53) Niu, M.; Cheng, D.; Cao, D. Understanding the Mechanism of Photocatalysis Enhancements in the Graphene-like Semiconductor Sheet/TiO ${ }_{2}$ Composites. J. Phys. Chem. C 2014, 118 (11), 5954-5960.DOI: DOI: 10.1021/jp412556r 


\section{For Table of Content Use Only}

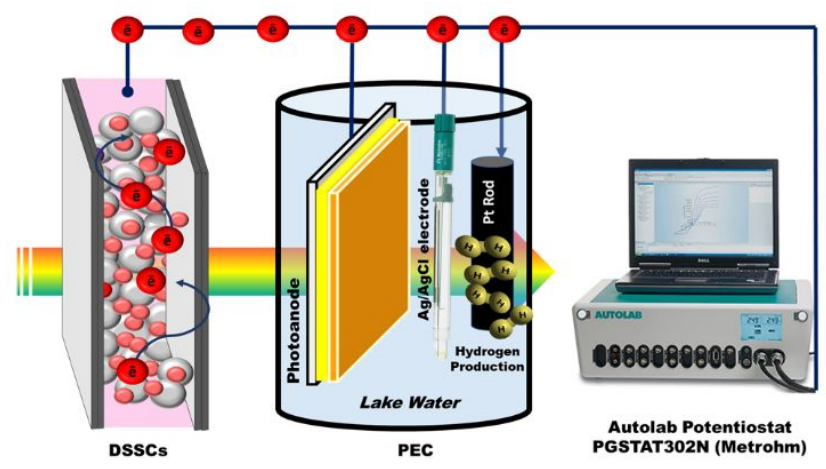

A study on the Photoelectrocatalytic Hydrogen Production from Lake Water via a novel g$\mathrm{C}_{3} \mathrm{~N}_{4} / \mathrm{BiVO}_{4}$ Microflower Photocatalyst. 


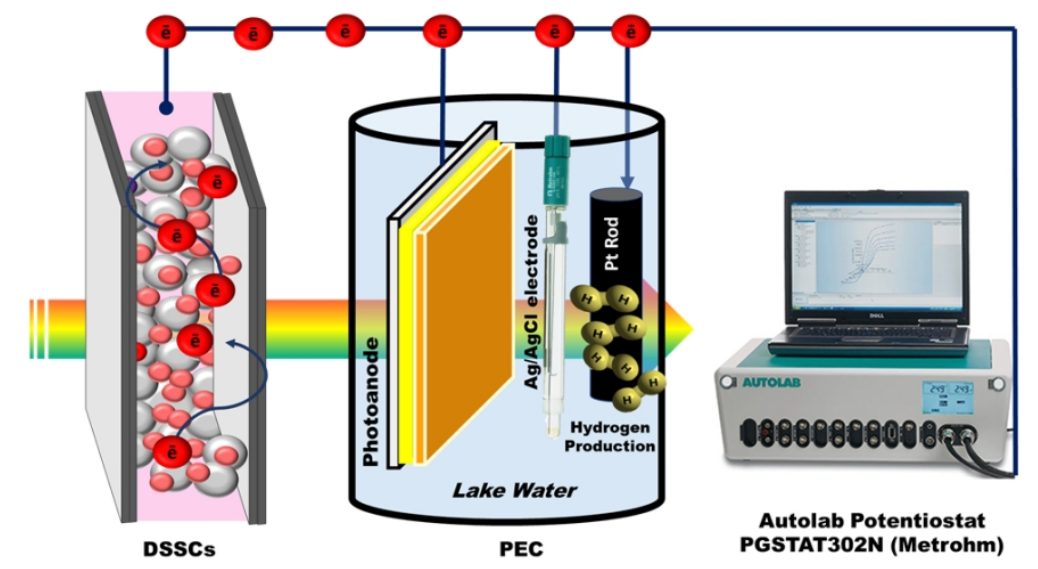

Schematic experimental setup used for measuring the photoelectrocatalytic hydrogen evolution performance of the $\mathrm{g}_{-} \mathrm{C}_{3} \mathrm{~N}_{4} / \mathrm{BiVO}_{4}$ microflower photocatalyst.

$338 \times 190 \mathrm{~mm}(96 \times 96 \mathrm{DPI})$ 